\title{
Valuation of Damages to Recreational Trout Fishing in the Upper Northeast Due to Acidic Deposition
}

\author{
J. E. Englin \\ T. A. Cameron \\ R. E. Mendelsohn \\ G. A. Parsons \\ S. A. Shankle
}

April 1991

Prepared for

National Acidic Precipitation Assessment Program

under a Related Services Agreement

with the U.S. Department of Energy

Contract DE-AC06-76RLO 1830

Pacific Northwest Laboratory

Operated for the U.S. Department of Energy

by Battelle Memorial Institute 


\title{
DISCLAIMER
}

This report was prepared as an account of work sponsored by an agency of the United States Government. Neither the United States Government nor any agency thereof, nor Battelle Memorial Institute, nor any of their employees, makes any warranty, expressed or implied, or assumes any legal liability or responsibility for the accuracy, completeness, or usefulness of any information, apparatus, product, or process disclosed, or represents that its use would not infringe privately owned rights. Reference herein to any specific commercial product, process, or service by trade name, trademark, manufacturer, or otherwise does not necessarily constitute or imply its endorsement, recommendation, or favoring by the United States Government or any agency thereof, or Battelle Memorial Institute. The views and opinions of authors expressed herein do not necessarily state or reflect those of the United States Government or any agency thereof.

\author{
PACIFIC NORTHWEST LABORATORY \\ operated by \\ BATTELLE MEMORIAL INSTITUTE \\ for the \\ UNITED STATES DEPARTMENT OF ENERGY \\ under Contract DE-AC06-76RLO 1830
}

Printed in the United States of America

Availahle to DOE and DOE contractors from the Office of Scientific and Technical Information, P.O. Box 62, Oak Ridge, TN 37831; prices available from (615) 576-8401. FTS 626-8401.

Available to the public from the National Technical Information Service, U.S. Department of Commerce, 5285 Port Royal Rd., Springfield, VA 22161. 
PNL-7683

UC -402

VALUATION OF DAMAGES TO RECREATIONAL

TROUT FISHING IN THE UPPER NORTHEAST DUE

TO ACIDIC DEPOSITION
J. E. Engl in
T. A. Cameron
R. E. Mendel sohn
G. A. Parsons
S. A. Shankle

April 1991

Prepared for National Acidic Precipitation Assessment Program under a Related Services Agreement with the U.S. Department of Energy Contract DE-AC06-76RLO 1830

Pacific Northwest Laboratory Richland, Washington 99352 


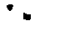

.

,

- 


\begin{abstract}
This report documents methods used to estimate economic models of changes in recreational fishing due to the acidic deposition. The analysis was conducted by Pacific Northwest Laboratory (PNL) and its subcontractors for the U.S. Environmental Protection Agency (EPA) and the U.S. Department of Energy (DOE) in support of the National Acidic Precipitation Assessment Program (NAPAP). The primary data needed to estimate these models were collected in the 1989 Aquatic Based Recreation Survey (ABRS), which was jointly funded by the DOE and the EPA's Office of Policy Planning and Evaluation.
\end{abstract}




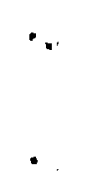

, 


\section{EXECUTIVE SUMMARY}

This report documents the methods used to develop economic models of recreational fishing and describes how these models were used to estimate the value of changes in acidic deposition. The analysis was conducted by Pacific Northwest Laboratory (PNL) and its subcontractors for the U.S. Environmental Protection Agency (EPA) and the U.S. Department of Energy (DOE) in support of the National Acidic Precipitation Assessment Program (NAPAP). The 1989 Aquatic Based Recreation Survey (ABRS), which was jointly funded by the DOE and the Economic Analysis Branch of the EPA's Office of Policy Planning and Evaluation (OPPE), involved the collection of data to develop economic models of recreation behavior. Data were collected on freshwater recreational trips made during the summer of 1989 by 5,724 randomly selected individuals in four Northeastern states: Maine, New Hampshire, New York (excluding New York City), and Vermont (Shankle et al. 1990).

Changes in acidic deposition are expected to impact fish populations through changing acidic stress levels, thereby changing catch rates of various species. An angler's economic well-being changes when a change in catch rate causes an angler to enjoy a site less (more) or results in a decision to change sites and travel farther (closer). Travel cost models are based on the premise that the cost of travel to a site can be used to represent the price of a recreational fishing site.

Two travel cost models were estimated in this study: the hedonic travel cost model and the random utility model. Both models use the same basic data, but they evaluate angler decisions differently. The random utility model provides estimates of changes in value per choice occasion based upon the relevant changes in the quality characteristics of the sites available to anglers. Anglers choose among the sites available to them by comparing the relative attributes of the sites. The hedonic travel cost model estimates the marginal willingness-to-pay for a marginal increase in each attribute. Anglers choose among sites by weighing the desirability of attributes against the cost of traveling to sites with the most desirable characteristics.

A difficulty in attempting to link biological and economic models of the effects of acidic deposition is that the economically relevant measure of 
acidification effects is not identical to the biological measure. The biological measure has to do with the abundance of fish, measured in terms of an acidic stress index (ASI). In order to value recreational fishing effects, changes in fish populations due to changes in ASI need to be translated into a measure that is directly equal to changes in behavior, catch per unit of effort (CPUE). In this study, CPUE is the number of fish caught in an hour.

The approach taken in this analysis was to develop a statistical relationship between the biological and the economic measure of fish population using the econometric technique of multiple regression analysis. Once the regression parameters were estimated, this linkage model was used to translate changes in ASI into changes in CPUE. The fundamental source of data for this analysis was the intersection data. These data included all fishing trips in the ABRS to lakes which were also part of the Eastern Lake Survey (ELS). The ELS contains the chemistry information needed to analyze the lakes under consideration. The intersection database contains data on 64 lakes, 143 anglers, and 1265 trips.

The expected growth or decline in the number of anglers is of considerable importance in estimating the size of the economic damage from acidic deposition to recreational fishing in New England. A participation model was used in this study to relate the number of fishing days to the CPUE figures, travel costs, and the demographic characteristics of the population. The intertemporal change in the composition of the population (the "baby boom") and the cross-sectional differences in angling opportunities were incorporated into the analysis. The econometric technique used to model this relationship was designed to improve the ability of conventional participation methods to address long-term trends and to provide a deeper level of insight than simple cross-sectional analysis can provide.

The participation model was estimated using data from the 1980 and 1985 National Surveys of Fishing, Hunting, and Wildlife-Associated Recreation (NSFHWR), which covers the outdoor recreation behavior of the general population of the entire United States. These surveys provided information on costs of fishing, catch, and regional characteristics. Data from 12 northeastern states were included in our analysis. 
The analysis consisted of six general steps. Step 1 involved calculating baseline (initial) ASI data for lakes in the recreational fishing sample for each of eight scenarios. Step 2 involved calculating initial CPUE values from the catch rate data on sports fish species in the fishing survey. The initial CPUEs for the trout species were then used in Step 3 to estimate a 1 inkage model and derive projected changes in CPUE due to changes in acidification. In Step 4, the two travel cost models were estimated using the recreational fishing data. The resulting parameter estimates of the travel cost models were used in conjunction with the forecasted changes in CPUE (from Step 3) associated with each scenario to estimate the per trip economic damages. In Step 5, the participation model was simulated to project changes in demographics and resulting angler participation for the years 2010 and 2030. Finally, in Step 6, the travel cost estimates were aggregated, and the participation model estimates were used to adjust the weights from the fishing sample to derive the total social value of recreational fishing in each of the years of interest.

The projected changes from acid deposition are generally smal1. These changes fall into three areas. One is the change in CPUE developed during Step 3. These changes range from a maximum of -0.86 catch per angling day reduction in brook trout due to current damages to an increase of 0.02 fish per angling day. These small differences tend to result in similarly small projected economic damages and changes in participation.

Participation in recreational fishing is predicted to rise by $12.5 \%$ by 2030. The bulk of the increase in participation, however, is the result of increasing income and retiring "baby boomers" rather than the impacts of acidic deposition. The final projections of the models indicate that economic damages to recreational fishing are likely to be small. The estimates of the current damages presented in Chapter 5 are approximately $\$ 2$ million or less each year. Under either control scenario (S1 or S4) examined in this study, the gains from controlling emissions are also modest. The largest social gain is predicted by the random utility model of recreational fishing. The random utility model predicts social gains of $\$ 9.7$ million in 2030 under the S4 scenario. The range of improvement in social welfare under the two models and either scenario is from $\$ 3.5 \mathrm{million}$ and $\$ 9.7 \mathrm{million}$ annually. 


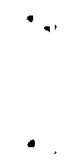<smiles>[Tl]</smiles>

. 


\section{CONTENTS}

EXECUTIVE SUMMARY ................... .

1.0 INTRODUCTION . . . . . . . . . . . . . . . . . . 1.1

1.1 NATIONAL ACIDIC PRECIPITATION ASSESSMENT PROGRAM . . . . 1.1

1.2 LINKING BIOLOGICAL AND ECONOMIC MODELS . . . . . . . 1.3

1.3 OVERVIEW OF THE ECONOMIC MODELS . . . . . . . . . . 1.4

1.4 THE PARTICIPATION MODEL . . . . . . . . . . . . 1.5

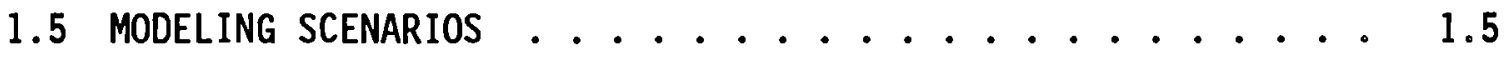

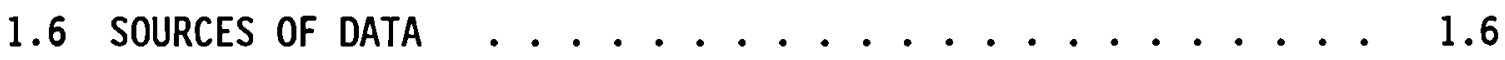

1.7 OUTLINE OF ANALYSIS . . . . . . . . . . . . 1.6

2.0 CATCH PER UNIT EFFORT ANALYSIS . . . . . . . . . . . 2.1

2.1 INTERSECTION DATA SET . . . . . . . . . . . 2.1

2.2 ACIDIC STRESS INDEX CALCULATIONS . . . . . . . . 2.2

2.3 CATCH PER UNIT EFFORT LINKAGE MODEL . . . . . . . . . 2.6

2.4 SUMMARY . . . . . . . . . . . . . . . 2.9

3.0 ESTIMATION OF TRAVEL COST MODELS . . . . . . . . . . . . . 3.1

3.1 HEDONIC TRAVEL COST MODEL . . . . . . . . . . 3.1

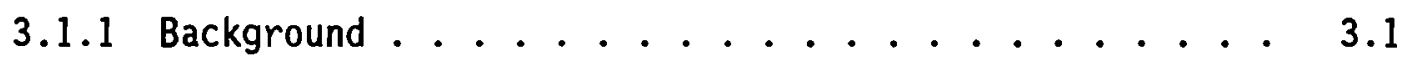

3.1.2 Theoretical Structure . . . . . . . . . . 3.3

3.1.3 Application ....................... 3.5

3.1 .4 Results . . . . . . . . . . . . 3.6

3.2 RANDOM UTILITY MODEL $\ldots \ldots \ldots \ldots$

3.2.1 Background ................. 3.10

3.2.2 Theoretical Structure ............ 3.10

3.2.3 Application .......................... 3.11

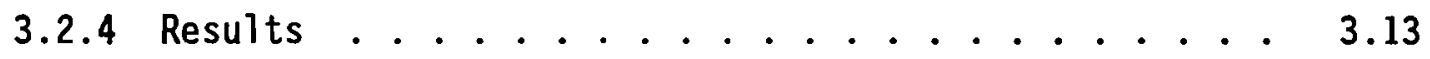




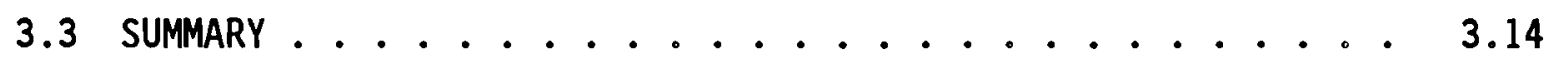

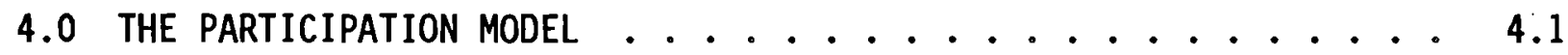

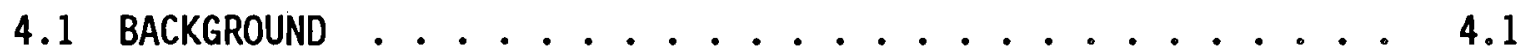

4.2 COHORT DATA DEVELOPMENT . . . . . . . . . . 4.1

4.3 APPLICATION .......................... 4.2

4.4 SUMMARY . . . . . . . . . . . . . . . . . . . 4.4

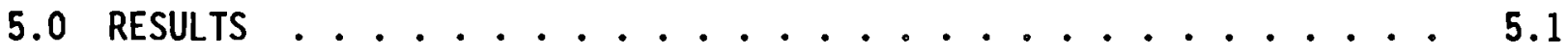

5.1 SOCIAL WELFARE CALCULATIONS .................. 5.1

5.2 RESULTS . . . . . . . . . . . . . . 5.1

5.2.1 Current Damages Scenario Results ......... 5.3

5.2.2 Sensitivity Analysis Results . . . . . . . 5.3

5.2.3 NPAP Scenario Results ............ 5.4

5.2.4 Differences in Model Estimates .......... 5.5

5.3 LIMITATIONS . . . . . . . . . . . . . . . . . . 5.6

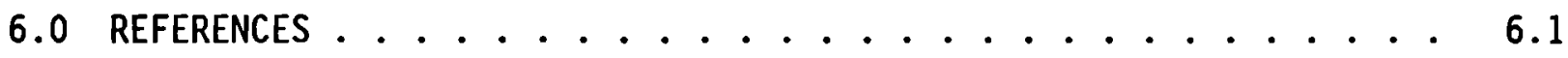

APPENDIX A - CPUE ANALYSIS RESULTS .............. A.1

APPENDIX B - TRAVEL COST MODELS . . . . . . . . . . . B. 1

APPENDIX $c$ - PARTICIPATION ANALYSIS RESULTS . . . . . . . . c.1 


\subsection{INTRODUCTION}

This report documents the methods used to estimate economic models of changes in recreational fishing due to acidic deposition. The analysis was conducted by Pacific Northwest Laboratory (PNL) and its subcontractors for the U.S. Environmental Protection Agency (EPA) and the U.S. Department of Energy (DOE) in support of the National Acidic Precipitation Assessment Program (NAPAP). The primary data needed to estimate these models were collected in the 1989 Aquatic Based Recreation Survey (ABRS), which was jointly funded by the DOE and the EPA's Office of Policy Planning and Evaluation (see Shankle et al. 1990).

\subsection{NATIONAL ACIDIC PRECIPITATION ASSESSMENT PROGRAM}

The 1990 NAPAP Integrated Assessment (IA) is concerned with understanding how acidic deposition impacts the environment and with evaluating the scale of the impact. One of the impacted physical environments is the aquatic environment. Aquatic environments subject to acidic deposition can suffer long-term changes in water chemistry, which affect the character and health of naturally occurring plants and animals. A part of NAPAP, the Aquatic Effects Research Program (AERP), examined the impacts on aquatic resources and was responsible for collecting current chemical and biological data and for forecasting changes due to acidification. The Eastern Lakes Survey (ELS) was the fundamental data source on the chemistry of the lakes under consideration. The ELS database contains data on 1,798 lakes in the Eastern Region of the United States, providing the first of the chemical-biological links in the AERP.

Another program in NAPAP, the Direct/Delayed Response Project (DDRP), is responsible for estimating regional biological effects of acidic deposition and for predicting future changes in aquatic resources associated with various deposition conditions. For any lake with adequate chemical and physical data, DDRP biological models allow the effects of acidic deposition scenarios on fish populations to be simulated.

The DDRP models can provide several biological measures of the abundance of fish. The most commonly used measures are those predicted by toxicity 
models, which quantify changes in fish survivability as a function of changes in acid-based chemistry under laboratory conditions. An acidic stress index (ASI) provides a measure of fish mortality as a function of changing $\mathrm{pH}$ and the concentration of aluminum and calcium. ASIs are scaled from $0 \%$ to $100 \%$, with $0 \%$ indicating that fish mortality is zero and $100 \%$ indicating complete loss of fish. Fish populations can be classified into three groups according to their ability to withstand acidic stress: sensitive species (rainbow trout), intermediate species (smallmouth bass, brown trout, and lake trout), and tolerant species (brook trout). Each of these groups has its own acidic stress index. The advantage of toxicity models is that they are based on controlled experimental data and so reflect only acidification impacts. This makes toxicity models ideal since they reflect changes in fish populations which are solely attributable to changes in acidity. These models are discussed further in Chapter 2.

NAPAP analysis is organized through a series of scenarios. These include three sensitivity scenarios that examine model performance under extreme circumstances, a current damages scenario that compares pre-industrial water acidification to current water acidification, and two policy scenarios known as S1 and S4. S1 and S4 are scenarios that simulate the effects of two possible philosophies about $\mathrm{SO}_{2}$ control legislation. Both scenarios focus on achieving about the same level of emissions in 2030. The important difference between the two scenarios is the time path of emission reductions.

The S1 scenario allows emissions to continue at current or slightly higher levels for the next twenty or so years. By 2010 emission are greater than they are 1990. In contrast, the $S 4$ scenario requires reductions from current emission levels in the near term. Under $\$ 4$, full emission reductions have been achieved by 2010 . The $S 4$ scenario is likely to require older power plants to be retro-fitted with emission control devices. By 2030 both scenarios are expected to achieve approximately the same level of emissions, with $\mathrm{Sl}$ being slightly higher. Figure 1.1 shows the time path of $\mathrm{SO}_{2}$ emissions to the year 2030 . 


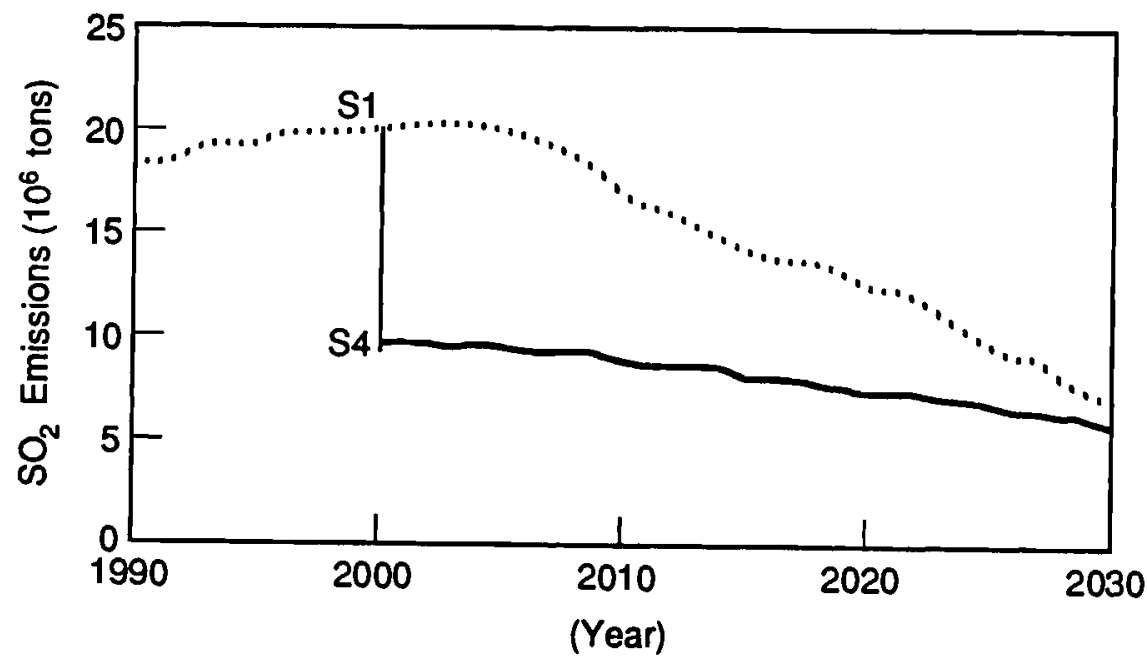

S9103118.1

FIGURE 1.1. $\mathrm{SO}_{2}$ Emissions to the Year 2030

\subsection{LINKING BIOLOGICAL AND ECONOMIC MODELS}

A difficulty in attempting to link biological and economic models of the effects of acidic deposition is that the economical effects are not identical to the biological effects. The biological measure has to do with the abundance of fish, measured in terms of an acidic stress index (ASI). In order to value recreational fishing effects, however, changes in fish populations due to changes in ASI need to be translated into an economically relevant and quantifiable measure. Economically relevant measures of abundance revolve around the quantity of catchable fish. The number of fish in a lake is not relevant to an angler if they are too small, or too hard to catch. The recreational quantity is the catch per unit of effort (CPUE). In the linkage model, CPUE is the number of fish caught in an hour.

There is, however, a relationship between the biological and economic measures of abundance. The more fish in a lake the greater the recreational catch. As the biological measures of abundance fall off, the CPUE also falls. The approach taken in this analysis was to develop a statistical relationship between the biological and the economic measures of fish population using multiple regression econometric techniques. Once the regression parameters are estimated, this linkage model translates changes in ASI into changes in 
CPUE. An independent linkage model was estimated for each fish sensitivity class. Chapter 2 details the calculation of baseline and projected ASIs and CPUEs for lakes in the sample.

\subsection{OVERVIEW OF THE ECONOMIC MODELS}

Changes in acidic deposition are expected to affect fish populations through changing acidic stress levels, thereby changing catch rates of various species. An angler's willingness-to-pay for a fishing trip changes when a change in CPUE causes an angler to enjoy a site less (more) or results in a decision to change sites and travel farther (less). The economic value of this change in catch rates is the willingness to pay by each angler to prevent the change, e.g., the reduction in catch rate. The special difficulty with recreational fishing is that this experience is rarely sold in an observable market. There are usually no "user fees" for recreational fishing. As a result, conventional approaches to measuring the economic value of goods and services cannot be applied to recreational fishing due to the lack of direct information on demand. However, demand for recreational trips can be inferred indirectly from the relationship between the quantity of trips chosen and the cost of private market goods that must be purchased to take the trip and gain access to the site.

Travel cost models are based on the premise that the cost of travel to a recreational fishing site acts as a price (value) for that site. Two travel cost models were estimated in this study: the hedonic travel cost model and the random utility model. Both models use the same basic data but they evaluate angler decisions differently. The random utility model provides estimates of changes in value per choice occasion based upon the relevant changes in the quality characteristics of the sites available to anglers. Anglers are assumed to choose among sites based on their relative values. The hedonic travel cost model estimates the marginal willingness-to-pay for a marginal increase in each attribute. Anglers choose among sites by weighing the desirability of attributes of sites against the cost of traveling to sites 
with the most desirable characteristics (see Shankle et al. 1990 for a complete discussion of the models). Chapter 3 discusses the travel cost models in greater detail.

\subsection{IHE PARTICIPATION MODEL}

Finally, a model is needed to assess the impact from acidic deposition on recreational fishing in New England and changes in the demographic composition of the population. Participation models provide a statistical estimate of the number of days that an individual chooses to spend fishing as a function of observable characteristics, including demographic characteristics, site characteristics, and economic information such as travel costs. A participation model was used in this study to relate the number of fishing days to the CPUE figures, travel costs, and demographic characteristics of the population (see Chapter 4). Both the intertemporal change in the composition of the population (the "baby boom") and the cross-sectional differences in angling opportunities were incorporated into the analysis.

\subsection{MODELING SCENARIOS}

NAPAP has defined two control scenarios for the purposes of projecting effects due to a range of hypothesized increases and reductions in acidic deposition. Aquatic, terrestrial, visibility, materials, and health effects can then be compared for common possible deposition scenarios. The first scenario ( $\mathrm{S} 1$ ) assumes no additional sulfur controls beyond those already legislated. The other scenario (S4) represents a reduction (from 1980) levels of 10 million tons.

Using the two travel cost models described above, the economic effects on recreational fishing due to changes in CPUEs were estimated. The changes in ASIs and then CPUE were forecasted for the years 2010 and 2030. Three additional scenarios were simulated to test the sensitivity of the economic models to changes in acidic stress. Taking current (1989) deposition levels as the baseline, three scenarios were forecast for the year 2030: a 30\% increase in deposition, no change, and a 50\% reduction from current deposition levels. A 
final analysis estimated the current damages to recreational fishing due to acidification in Adirondack lakes. In total, eight different scenarios were simulated.

The dollar estimates of damages or improvements produced for these scenarios are for a single point in time. The values are annual damages for the year under consideration, i.e., 2010 or 2030, and are reported in terms of 1989 dollars.

\subsection{SOURCES OF DATA}

Two data sets were utilized in addition to the ELS to provide data on anglers and lakes. The first is a subset of the ABRS, the Freshwater Recreational Fishing Survey (FRFS), that covers 14,790 trips to 3,362 fishing sites by 1,144 anglers from four Northeastern states: Maine, New Hampshire, New York (excluding New York City), and Vermont (Shankel et al. 1990). Respondents who participated in freshwater fishing during the summer of 1989 were questioned about their fishing behavior. The data collected include site, angler, and trip characteristics. Since these data are based on a random sample, they can be used to generate estimates of the characteristics of the fishing population. These data were used to estimate the two travel cost models.

The second data set was the National Survey of Fishing, Hunting, and Wildl ife-Associated Recreation (NSFHWR), which covers the general population of the entire United States. NSFHWR data include information on costs, catch, and regional characteristics. Data from 12 states were included in this analysis. These data were used to estimate the participation model. The welfare estimates produced by the travel cost models were adjusted using the estimates produced by the participation model.

\subsection{OUTLINE OF ANALYSIS}

The analysis documented in this report consists of five general steps as indicated in Figure 1.2. The figure indicates which chapter documents each step. Chapter 2 describes the CPUE analysis, including estimation of initial and projected ASIs and the biological-economic linkage model that relates 


\section{Chapter 2}

Chapter 3
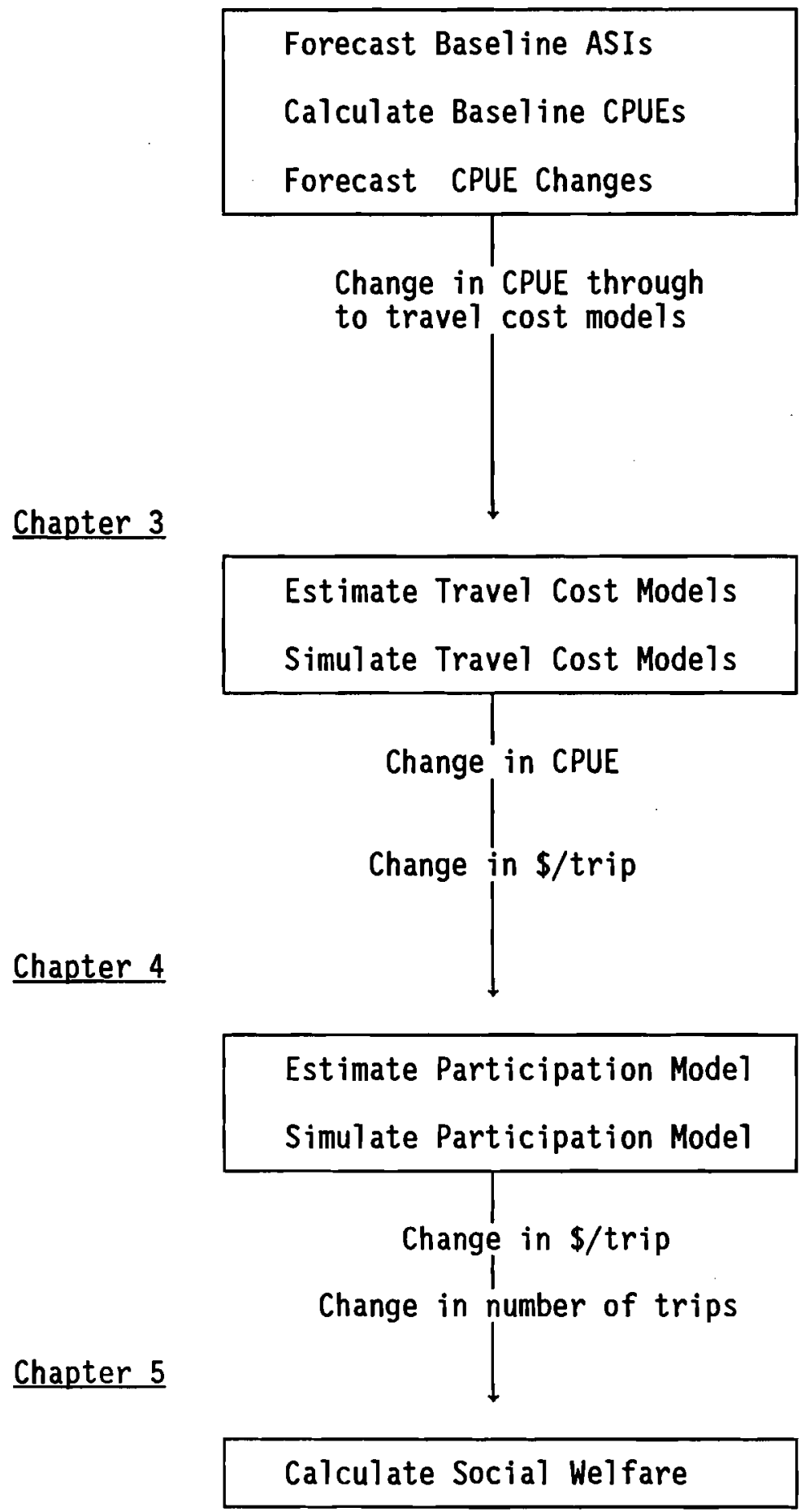

FIGURE 1.2. Relationship between Chapters and the Analysis 
these changes in ASI to changes in CPUE. The forecasting and linkage models were based on a data set which included 64 lakes, 143 anglers, and 1265 angling trips. This part of the analysis produced baseline ASI and CPUE data and projected changes in ASI and CPUE for all visited lakes in the recreational fishing sample. This was done as follows:

- A model was used of the relationship between the acidic stress to which various fish species are exposed and watershed characteristics to forecast the initial (current) ASI for tolerant, intermediate, and sensitive trout species in each lake in the recreational fishing sample.

- Catch rate data from the recreational fishing survey were used to calculate baseline (current) CPUE values for game fish for lakes in the sample. This calculation was done by dividing the total catch from all anglers in a lake by the total hours all anglers spent fishing on the lake.

- A model of the relationship between ASI and CPUE was used to estimate the percentage change in CPUE for each lake visited in the recreational fishing sample for each of the eight scenarios described above.

Chapter 3 documents the travel cost model estimations and presents the resulting welfare values for each model for each of the scenarios. Data on catch rates for four species of trout from the Recreational Fishing Survey were used in conjunction with forecast changes in CPUE to estimate the two travel cost models for the eight scenarios. For each of the eight scenarios:

- The hedonic price model was simulated to produce the marginal value associated with an increase in trout catch rates, i.e., how much an angler would be willing to pay to catch one more trout per hour per trip under the eight simulated changes in CPUE. These values were then expanded to the population using the Recreational Fishing Sample weights. This process generates the hedonic travel cost model estimates of changing welfare under each of the scenarios.

- The random utility model was simulated to estimate the dollar equivalent of the individual's change in expected utility associated with a fishing trip due to a change in catch rate for each scenario. Seasonal welfare estimates are obtained by multiplying this per trip welfare estimate by the individual's total number of trips. The sample average welfare estimate is then calculated and expanded to the population using the Recreational Fishing Sample weights. This process generates the RUM estimates of changing welfare under each of the scenarios. 
Chapter 4 explains the role of the participation model and its

specification. The participation model was used to adjust the estimates from chapter 4, essentially the sample weights, to reflect:

- the effect of changes in catch rates on the total number of anglers and the number of days they fish

- the demographic composition of the population as it changes over time.

Chapter 5 details how the model outcomes of previous chapters were aggregated to derive an estimate of the change in social value for recreational fishing impacts under the different deposition scenarios. 
$\ddots$
.

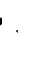

. 


\subsection{CATCH PER UNIT EFFORT (CPUE) ANALYSIS}

This chapter outlines the approach used to calculate catch per unit effort (CPUE) from the data gathered in the Recreational Fishing Survey. These numbers are the crucial measures of the effect of acidic deposition on recreational fishing behavior. CPUEs were calculated for each of the scenarios described in the previous chapter. Projected changes in CPUE depend on forecasted changes in biological abundance as specified by the Aquatics Effects Research Program (AERP) models. The changes in CPUE were then used as independent variables in the two travel cost models to estimate the total social value of the changes (described in Chapter 3 ). The simulated changes in CPUE will result in changes in fishing site attributes. The travel cost models will calculate the willingness-to-pay by anglers to avoid damages or obtain improvements for the simulated CPUE.

\subsection{INTERSECTION DATA SET}

This section describes the data used by the Acidic Stress Index (ASI) forecasting equations and the CPUE equation analysis. The data set used was an intersection data set of lakes from the Aquatic Based Recreation Survey (ABRS) and the Eastern Lakes Survey (ELS). This intersection data set was developed in four steps. In Step 1, the ELS lakes that were visited by anglers in the ABRS data were identified using the lake/pond name and location. The location was identified from the town name and distance from the town in the ABRS data. Longitude and latitude were used to locate sites in the ELS data. Every lake or pond visited by the anglers in ABRS data was found on state maps and examined as a possible match using this technique. In Step 2, the angling portion of the data was organized into a trip-oriented file. Every day trip to a pond or Take in the ELS data set was extracted from the main data files. Step 3 merged the angler characteristics, the site characteristics, and the trip characteristics into a single record. In this file each observation is a trip to a lake or pond. The final step was to append the ELS data from each lake or pond onto each record. The data included a11 of the chemical and watershed characteristics in the ELS data set. 
Figure 2.1 shows the relationship between each of the data sets used in this analysis. The ABRS is the full set of lakes that people in the sample actually visited, the ELS is based upon all lakes. As part of AERP, the Direct/Delayed Response Project (DDRP) developed biological models to predict changes in acidic stress associated with varying deposition levels. DDRP lakes are a subset of ELS lakes.

Table 2.1 shows the data set. Of the 1,144 anglers in the recreational fishing sample, about $12 \%$ are included in the intersection data set. The sample includes about $8 \%$ of the total trips taken. Both of these represent small fractions of the total angler sample. Only about $6 \%$ of the ELS lakes in the region are included in this study. This drop likely results from the difference in sample frames. The ELS lakes included only lakes greater than 4 hectares in area. Anglers, however, visit lakes less than 4 hectares. Because of the way the two data sets were constructed, any lake less than 4 hectares cannot be included in the intersection data. There is no way to precisely identify the percentage of lakes under 4 hectares actually visited by anglers.

There was a wide range of fish species targeted (i.e., preferred by anglers) by anglers, who used three basic kinds of gear: $38.9 \%$ of the anglers used fly fishing gear on the trip, $28.7 \%$ used spinning gear, and $27.1 \%$ used bait-casting equipment. The remainder used miscellaneous equipment.

Table 2.2 shows two things: the fish species anglers expect to catch during a number of trips and the number of anglers expecting to catch those species.

\subsection{ACIDIC STRESS INDEX (ASI) CALCULATIONS}

The ASIs were calculated for lakes in the intersection data set for a tolerant, an intermediate, and a sensitive index. Each index represents experimental survival rates of representative species of fish fry under different water chemistry conditions. The tolerant index is based on brook trout fry survival, the intermediate index on smallmouth bass fry survival rates, and the sensitive index on rainbow trout fry survival rates. Table 2.3 shows the distribution of ASIs in the intersection data. As can be seen, there was 


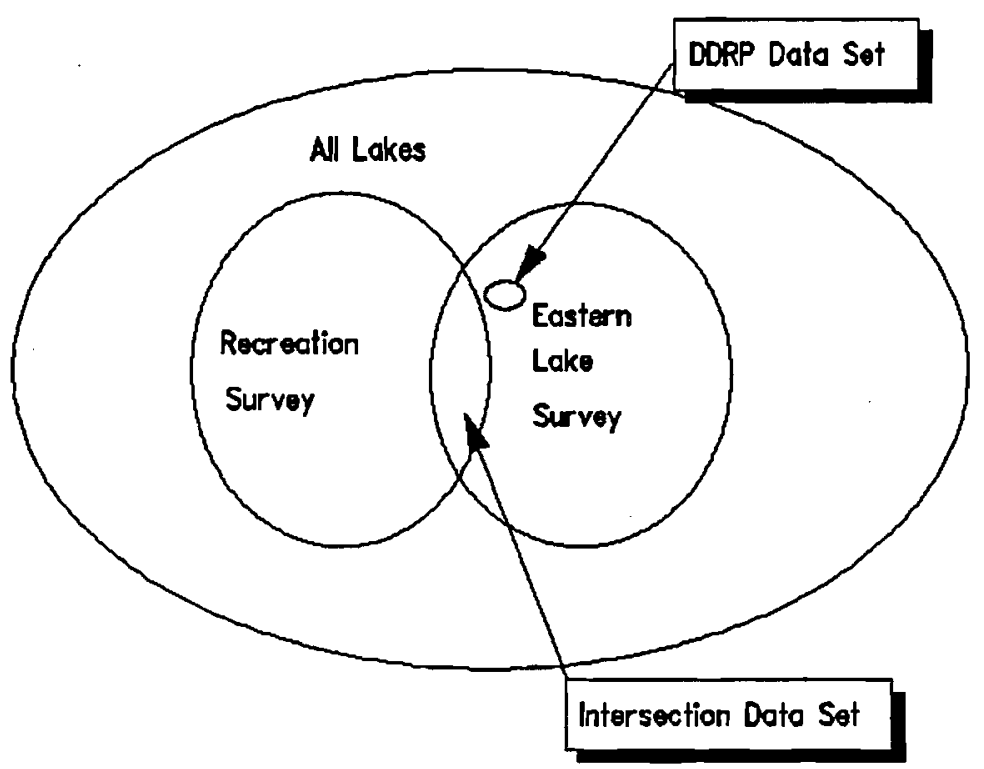

FIGURE 2.1. Diagram of the Relationships Between the Data

IABLE 2.1. The Number of Individual Lakes, Anglers, and Trips in the Intersection Data Set

\begin{tabular}{|c|c|c|c|c|}
\hline Dimension & Maine & New York & New Hampshire & Vermont \\
\hline Lakes & 23 & 12 & 15 & 14 \\
\hline Anglers & 39 & 62 & 23 & 19 \\
\hline Trips & 586 & 251 & 361 & 67 \\
\hline
\end{tabular}


TABLE 2.2. Intersection Data Set Distribution of Trips by Trout Species Expected to be Caught

\begin{tabular}{lccc} 
Species & & Number of Trips & Number of Anglers \\
\cline { 1 - 2 } Brook Trout & 299 & 24 \\
Brown Trout & 405 & 17 \\
Lake Trout & 250 & 24 \\
Rainbow Trout & 237 & 34
\end{tabular}

some fishing in lakes under the maximum degree of stress. However, fishing in these lakes tended to be for species other than trout species.

For lakes in the intersection data set, ELS data provided the necessary chemical and watershed characteristics, so calculating ASIs was a straightforward exercise. Unfortunately, the sample is small relative to all lakes available for fishing in the Upper Northeast. Therefore, the initial ASIs and the changes in ASIs had to be forecasted for lakes for which there was incomplete information. Forecasting models for this purpose were developed by regressing ASIs in the intersection data on lake characteristics.

The ASI forecasting model predicts current ASI indices on a lake by lake basis. These models were constructed using the entire intersection data set.

TABLE 2.3. Calculated Mean, Maximum and Minimum ASI Values for the Three Sensitivity Classes

\begin{tabular}{|c|c|c|c|}
\hline ASI & Mean & Minimum & Maximum \\
\hline Sensitive & 15.65 & 0.0 & $100.0^{(a)}$ \\
\hline Intermediate & 3.17 & 0.0 & 100.0 \\
\hline Tolerant & 0.12 & 0.0 & 50.4 \\
\hline
\end{tabular}

(a) 100 indicates that $100 \%$ of fish fry died in 1aboratory experiments with the same water chemistry. 
The explanatory variables used in this analysis include only those variables that were present in the ABRS data set. This allows the models to be used to forecast the ASI starting indices using the ABRS data. The key independent variables included in the model were: state, pond or lake, percentage of watershed in leafy trees, percentage of watershed in pine trees, percentage of watershed in meadows, percentage of watershed that is agricultural land, subjective description of the weediness of the lake, visibility, and whether boating or swimming was included on the trip.

The final regression for sensitive species was fit with a linear functional form. The final regression for intermediate species was fit using a semi-logarithmic functional form. No model was constructed for the tolerant ASI class because there was virtually no evidence that anglers targeting brook trout were visiting acidic lakes. Only three lakes which were targeted for brook trout trips had non-zero tolerant ASI indices. (The highest ASI in a visited lake was 0.63 , which is essentially zero.) Appendix A, Table A.2, gives the regression results and variable definitions for the sensitive and intermediate specifications.

Once the forecasting models were constructed, the first step in the analysis was to forecast the beginning sensitive and intermediate ASI for each lake visited in the Recreational Fishing Survey. For those lakes with a negative predicted ASI, the ASI was reset to zero. All of the tolerant ASIs had a beginning value of zero. Table 2.4 shows the baseline forecasted ASI indices for the full angler data.

DDRP biological models provide data on forecasted ASI shifts for each of the deposition scenarios considered in this study. These estimates were

TABLE 2.4. Forecasted Baseline ASI Indices for all ABRS lakes

\begin{tabular}{lcccc}
\multicolumn{1}{c}{ Index } & & Mean & Minimum & Maximum \\
Sensitive & & 0.52 & 0.21 & 17.50 \\
Intermediate & 0.24 & 0.21 & 7.67 \\
Tolerant & 0.00 & 0.00 & 0.00
\end{tabular}


calculated for a random sample of lakes in the ELS. Although the DDRP lakes are not part of the intersection data set, they are a random sample, so these changes in ASI can be used to describe the population of lakes in the Northeastern states. Table 2.5 gives the estimated changes in ASI for the current damage scenario for each ASI class. The changes in the ASIs of Adirondack 1 akes between historical levels (the 1844 estimate) and the "current" (1984) ASI range between a small estimated decrease (improvement) in tolerant ASI and a substantial increase (deterioration) in the intermediate ASI. The estimated ASI shifts for all eight scenarios are in Appendix A, Table A.4.

\subsection{CATCH PER UNIT EFFORT (CPUE) LINKAGE MODEL}

CPUE must be linked to a measure of biological abundance to make it useful in a linked analysis. One way to estimate the relationship between CPUE and biological abundance is through observations of individual anglers at lakes where the biological quantities are known. Equation (1) shows a relationship that can be applied to the intersection data set discussed in Section 2.2.

$$
\text { Individual Catch per Hour }=\alpha_{0}+\alpha_{i} z_{i}+\alpha_{j} z_{j}+\alpha_{k} \text { ASI }
$$

where $z_{\mathbf{i}}=$ individual characteristics (ABRS data)

$$
\begin{aligned}
& z_{j}=1 \text { ake/site characteristics (ELS data) } \\
& z_{k}=\text { ASI (DDRP models). }
\end{aligned}
$$

This equation predicts an individual's catch as a function of personal characteristics $\left(z_{i}\right)$, the site characteristics $\left(z_{j}\right)$, and the ASI. Another

\begin{tabular}{|c|c|c|c|}
\hline ASI Class & 1844 ASI & 1984 ASI & Delta AS. \\
\hline Sensitive & 0.25 & 4.2 & +4.0 \\
\hline Intermediate & 33.23 & 42.15 & +8.92 \\
\hline Tolerant & 69.03 & 68.07 & -1.04 \\
\hline
\end{tabular}

TABLE 2.5. Estimated Changes in ASI for the Three Sensitivity Classes in the Current Damages Scenario 
equation had to be estimated for each of the trout species under consideration, because different species are found in different lakes, different species are more difficult to catch than others, and different species are sought by anglers with different personal characteristics. The full estimation results are reported in Appendix A, Table A.5.

The most significant numbers produced by these regressions are the values of $\alpha_{k}$, the coefficient of the ASI variable. The value of this coefficient represents the change in CPUE associated with a unit change in ASI. Multiplying $\alpha_{k}$ by the forecasted change in ASI yields the change in CPUE. Table 2.6 gives these changes for each trout species. The rainbow and brown trout catch is not particularly responsive to changes in ASI. The equations are estimated on data that have a broad range of ASI and CPUE.

The lake trout catch equation shows a responsive relationship between the changes in catch and the ASI. This relationship is also estimated over a limited range of ASI. While the lakes in the intersection data set exhibited a range of intermediate ASIs, the range in lakes where lake trout were targeted is less broad. This coupled with the low catch rates observed for lake trout suggest that the lake trout parameter should be treated with some caution. It should be noted, however, that the lakes typically inhabited by lake trout are large. These lakes tend to be relatively resilient in the face of acidic deposition, and so do not exhibit large changes in ASI.

The brook trout relationship is suspect. The relationship indicates that a 1 unit increase in ASI will decrease the catch by 4.98 fish per hour. This is not plausible. An ASI of 1 , however, is nearly twice the largest tolerant ASI in the intersection data set. When interpreting brook trout CPUE simulation results, one needs to be aware that many changes in ASI, even smal1 ones like $1 \%$, are out of the range of observed data. The brook trout parameter is not robust and cannot be applied to as wide a range of chemistry changes as the other CPUE regressions. 
TABLE 2.6. Change in CPUE for a Unit Change in ASI (a)

$\begin{array}{lll}\text { Species } & \text { Change in CPUE } \\ \text { Rainbow } & -0.01 \\ \text { Brook } & -4.98 \\ \text { Brown } & -0.07 \\ \text { Lake } & -1.98\end{array}$

(a) Evaluated at the mean of the data.

Actual CPUEs for each species for each lake in the sample were calculated using data (i.e., average catches per day at each lake and the total number of hours fished at each lake) from the Recreational Fishing Survey. The calculation is straightforward, as indicated in the following equation:

$$
\text { Actual CPUE }=\text { Total Catch/Total Hours Fished }
$$

Using the baseline CPUEs as starting points, the CPUEs for each scenario ASI were calculated for each lake. This step essentially entailed multiplying the baseline CPUE for each lake by the percentage change in ASI $\left(\alpha_{k}\right)$ forecasted for each scenario. This results in the percentage change in the predicted CPUE. Table 2.7 shows the change in CPUE associated with three NAPAP scenarios. One is the current damages scenario. This is the difference between current CPUE and the CPUE with no acidification damages. The second set of NAPAP scenarios are future emission reduction scenarios. The table shows the changes in CPUE for the years 2010 and 2030 under two programs of reduced emissions.

There are two important features of these results. First, the changes in recreational CPUE resulting from changes in deposition are smal1. Most of the changes are in hundredths or thousands of fish caught per hour of fishing. The single largest change $(-0.86)$ is in the reduction of brook trout CPUE 
TABLE 2.7. Average Percentage Change in Catch per Unit Effort for Three
NAPAP Scenarios

\begin{tabular}{|c|c|c|c|c|c|}
\hline \multirow[b]{2}{*}{ Species } & \multirow[b]{2}{*}{ Current Damages } & \multicolumn{2}{|c|}{ S1 } & \multicolumn{2}{|c|}{ S4 } \\
\hline & & 2010 & 2030 & 2010 & 2030 \\
\hline Brook Trout & -0.86 & -0.025 & 0.0 & 0.0 & 0.0 \\
\hline Brown Trout & -0.01 & -0.001 & +0.023 & +0.002 & +0.0026 \\
\hline Rainbow Trout & -0.0002 & -0.0004 & +0.0007 & +0.0009 & +0.001 \\
\hline Lake Trout & -0.78 & -0.025 & +0.016 & +0.01 & +0.021 \\
\hline
\end{tabular}

(a) Current damages, S1 and S4 are three scenarios examined by NAPAP. They are briefly described in Section 1.1.

today in comparison with the brook trout CPUE under historical water chemistry. Second, brook trout receives special treatment in the analysis. Since no forecasting model of tolerant ASI was constructed (the intersection data set included almost no lakes that were under any measurable stress) beginning tolerant ASIs were set to zero for a11 lakes. Therefore, there can be no improvement in brook trout conditions regardless of any changes in deposition. This assumption is valid for S1 2030, S4 2010, and S4 2030. In addition, the simulated change in CPUE for the current damages scenario and S1 2010 are suspect. Since so few lakes with positive tolerant ASI indices are visited by anglers, the CPUE equation is not robust.

\subsection{SUMMARY}

This chapter documented how initial and projected changes in ASI were estimated for all lakes visited in the Recreational Fishing Survey. It described how these numbers were used in conjunction with catch rates from the fishing survey to estimate a linkage model to forecast changes in CPUE due to acidification for each of the eight deposition scenarios. Chapter 3 describes how these forecast changes in CPUE are used together with estimates produced by the travel cost models to calculate the value of recreational fishing trips. 
'

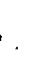




\subsection{ESTIMATION OF TRAVEL COST MODELS}

This chapter describes how the parameters of two travel cost models, the hedonic travel cost model and the random utility model, were estimated and used to derive values associated with changes in angler welfare due to different acidic deposition scenarios. Both models assume that the cost of travel to a site acts like price but they describe angler decisions differently. (a) Inputs for the model estimations were data from the Recreational Fishing Survey on site characteristics and catch rates for different species of fish. (For a detailed discussion of the data collected to estimate the travel cost models, see Shankle et al. 1990). The forecast changes in ASI (see Chapter 2) are linked to changes in CPUE, which result in changes in recreational fishing behavior. The changes in fishing behavior result in increases or decreases in the individual's welfare. These welfare changes are converted to dollar measures, namely, willingness-to-pay (WTP) to avoid damage or improve fishing conditions for an average individual for a fishing trip.

\subsection{HEDONIC TRAVEL COST MODEL}

The hedonic travel cost model directly estimates the value of specific site characteristics to an angler. The parameters of the model are estimated using standard econometric regression techniques applied to data on sites and anglers from the Recreational Fishing Survey. The output of the model is the change in an average angler's WTP for a trip (i.e., the change in angler welfare) due to changes in acidic deposition. The individual welfare changes can then be aggregated to produce a social welfare estimate.

\subsubsection{Background}

The hedonic travel cost model is designed to value recreational site characteristics. The model assumes potential anglers choose from among a broad set of sites that offer a variety of site attributes. Given the price

(a) For a detailed discussion of the theoretical basis for the economic valuation of recreational fishing effects, see Englin and Kealy (in press). "Assessing the Effects of Acidic Deposition/Air Pollution on the Aquatic Environment." 
of each attribute (i.e., how far an angler must drive to get more of any site attribute) each angler settles for the desired amount of each attribute and picks the single site that most closely embodies this choice.

The actual sites visited will vary across anglers and, because different anglers want different attributes, the chosen site will differ among anglers who face the same set of prices (i.e., who travel from the same location) from the same origin (the location of home). As origins vary, different destinations become near and far. The choices (prices) facing anglers from different origins will therefore vary. Some people will be "lucky" and live close to a great rainbow trout fishing site. An angler who happens to live close to the rainbow trout stream will have low prices for rainbow trout catch rate whereas one who lives far away from these streams will face higher prices for this attribute. These varying opportunities result in anglers from different origins making different observed choices of destinations.

Changes in acidic precipitation are expected to affect directly or indirectly the fish populations at various lakes and thus the catch rate of various species of freshwater fish at these lakes. The economic value of this change is measured by each angler's WTP to prevent the change. WTP is the amount of income the angler would give up rather than experience a reduction in catch rate. If the change in catch rate is small (marginal), the change can be measured by the incremental distance traveled to improve catch. That is, the loss will be equal to the extra cost an angler would have to pay to visit a site with slightly higher catch rates (or the reduction in travel cost associated with choosing a site with slightly lower catch rates).

Because a site's catch rate is shared by all anglers at a site, the value of a change in catch rate is worth what all the anglers who go to that site as a group are willing to pay. Thus, site values are the sum of individual WTPs for all visitors. WTP will vary across species and origins. WTP will also vary depending upon the size of the change in catch rates and the initial level of catch rate. Individual WTPs will vary because of differences in socioeconomic characteristics and because of origins.

Further, the value of a drop in catch rates at a single site will also depend upon the alternative sites available. If there are alternative sites 
of almost comparable quality, the reduction at the affected site will have only a limited effect on the angler who switches to the next best site. On the other hand, if there are no close substitutes, the angler may still have to stay at the site even after the drop in quality.

Changes in site attributes, especially if they are regional in nature, may also affect the frequency at which anglers visit any site. Large decreases in catch rates for favorite species, for example, may reduce overal1 trips. Reductions in trips will reduce the number of anglers actually visiting any one site. The value of catch could, therefore, fall as there are fewer visitors willing to pay to prevent site deterioration.

\subsubsection{Theoretical Structure}

The hedonic travel cost model (see Brown and Mendelsohn 1983) focuses on valuing the characteristics of recreation sites. Each site is viewed as a bundle of attributes (e.g., fish species, fish size, campgrounds, access) with the travel cost being the purchase price of this bundle. The travel cost may be apportioned among the attributes of the sites if quantities of attributes and travel costs vary across the sites.

The first stage of the hedonic travel cost model seeks to explain why people from a particular origin select certain recreation sites to visit. The travel cost that an individual is willing to incur to visit a specific site is postulated to be a function of the attributes of the site, as in the following equation:

$$
T C=f\left(q_{j}\right)
$$

where TC is travel costs and $q_{j}$ is the vector of attributes at the site. Clearly residents of any particular origin need not visit all sites. Some sites will not be worth the travel cost incurred in visiting them and, therefore, will not be visited. Equation (1) should be estimated for each origin. The data used in this analysis should include only the sites visited and their characteristics as observations. In equilibrium for all sites visited, the 
travel costs will equal the value of all the attributes. The marginal travel cost associated with the acquisition of an additional unit of an attribute is the derivative of Equation (1) with respect to that attribute.

Equation (2) shows a linear version of Equation (1). The estimated coefficients $\left(p_{j}\right)$ of the vector of attribute quantities $\left(q_{j}\right)$ represent the marginal willingness-to-travel for the corresponding attributes.

$$
T C=a+p_{j}^{*} q_{j}
$$

Equivalently, those coefficients are the implicit, or hedonic, prices of the attributes. As was discussed in the background section, the hedonic prices can be used to value small changes in quantity. Large changes in quantities require the use of a demand curve.

Demand curves follow directly from the first stage of the hedonic travel cost model. Since each origin faces a different travel cost structure, a second stage involves regressing the quantities of characteristics on the estimated implicit willingness to travel reveals the demand function for a given attribute:

$$
q_{i}=f\left(p_{j}, p_{j}, w_{k}\right)
$$

where $q_{j}=$ quantity of attribute $i$

$$
\begin{aligned}
& p_{j}=\text { estimated implicit price } i \\
& p_{j}=\text { estimated implicit price of substitutes } \\
& w_{k}=\text { demand shift variables. }
\end{aligned}
$$

The demand system shown in Equation ( 3 ) is found by estimating the relationship between the quantity of each attribute chosen by the angler and the incremental travel cost incurred by the angler to obtain those quantities along with various demand shift variables. 


\subsubsection{Application}

A variety of different exploratory specifications of Equation (2) were attempted using catch rates from the Freshwater Recreational Fishing Survey as independent variables in a hedonic price regression. (Appendix B documents these exploratory regressions in detail.) Other features of the site were also included in the analysis but did not receive as intensive analysis since they are not subject to change from acidic deposition. These included attributes such as the percent of different forest types around the water body, whether the water body was a pond, the visibility at the site, and the cleanliness of the site. The construction of the variables is reported in Appendix B.

The final regression specification included nine variables: rainbow trout CPUE, brown trout CPUE, brook trout CPUE, lake trout CPUE, weeds, trophy, pond, no garbage, and a constant. Catch rates were specified as mean catch per unit effort (CPUE); CPUEs were averaged over all anglers in the fishing survey. (Calculation of CPUEs is described in Chapter 2.)

Table 3.1 indicates the number of significant positive and negative coefficients for each explanatory variable. Twenty-nine counties had sufficient observations to support the final model. (The results for all 29 counties are given in Appendix B, Table B.2.) These results indicate a preference for rainbow trout, trophy fish, ponds, and no garbage at the site. The value of these coefficients indicates the number of miles traveled for one unit more of each characteristic. When multiplied by the travel cost, the result is the value paid by anglers in each county for an incremental unit of the attribute. These values are the hedonic prices for the site characteristics.

Briefly, Table 3.2 gives the incremental willingness-to-travel (the hedonic prices) for two illustrative counties, Somerset County, Maine, and Bennington County, Vermont. Both counties show a significant incremental (marginal) willingness-to-travel to obtain a pond and a trophy lake, regardless of species. The Somerset regression shows a negative marginal WTP for 
TABLE 3.1. Number of Significant Positive and Negative Coefficients in the First Stage of the Hedonic Travel Cost Model Coefficient

\begin{tabular}{lrrr}
\cline { 1 - 1 } \multicolumn{1}{c}{ Attribute } & & $(+)$ & $(-)$ \\
Rainbow Trout CPUE & & 10 & 6 \\
Brown Trout CPUE & 8 & 12 \\
Brook Trout CPUE & 10 & 9 \\
Lake Trout CPUE & 9 & 8 \\
Weeds & 11 & 9 \\
Trophy & 10 & 3 \\
Pond & 13 & 9 \\
Shore Litter & 11 & 9
\end{tabular}

additional brown trout CPUE while Bennington shows a positive marginal WTP for brown trout CPUE. It should be noted that both counties could have positive total WTP for brown trout CPUE. (a)

\section{1 .4 Results}

Figure 3.1 shows the basic steps needed to use the parameters of the hedonic travel cost model to value changes in CPUE. To calculate the value of the change in CPUE associated with a change in deposition, the hedonic price parameters for each county are multiplied by the cost per mile. This result is then multiplied by the projected change in CPUE (calculated from the physical data as described in Chapter 2) on a species by species basis for each lake visited by anglers from that county. These values are summed over all counties and divided by the total number of trips in order to calculate an average dollars per trip value associated with the model (see Appendix B).

(a) Engl in and Mendelsohn (in press) "An Hedonic Travel Cost Analysis for Evaluation of Multiple Components of Site Quality: The Recreation Value of Forest Management, " Journal of Environmental Economics and Management discuss the interpretation of negative coefficients in hedonic travel cost regressions. 
TABLE 3.2. Incremental Willingness-to-Travel for Two Counties (miles)

\begin{tabular}{|c|c|c|}
\hline \multirow{2}{*}{$\begin{array}{c}\text { Site } \\
\text { Characteristic } \\
\end{array}$} & \multicolumn{2}{|c|}{ County } \\
\hline & Somerset & Bennington \\
\hline Rainbow Trout CPUE & -13.48 & $11.83^{(a)}$ \\
\hline Brown Trout CPUE & -9.22 & $3.36^{(a)}$ \\
\hline Brook Trout CPUE & 0.43 & $-1.61^{(a)}$ \\
\hline Lake Trout CPUE & 8.23 & -5.13 \\
\hline Weeds & $3.35^{(b)}$ & 11.89 \\
\hline Trophy & $12.16^{\text {(b) }}$ & $19.48^{(a)}$ \\
\hline Pond & $14.68^{(b)}$ & $10.63^{(b)}$ \\
\hline Shore Litter & 0.43 & $5.94^{(a)}$ \\
\hline $\begin{array}{l}\text { No. of Trips } \\
\text { R-Square } \\
\text { Corrected R-Square }\end{array}$ & $\begin{array}{l}500 \\
0.10 \\
0.09\end{array}$ & $\begin{array}{r}45 \\
0.60 \\
0.52\end{array}$ \\
\hline $\begin{array}{l}\text { (a) Significant at } \\
\text { (b) Significant at }\end{array}$ & $\begin{array}{l}0.05 \mathrm{le} \\
0.10 \mathrm{le}\end{array}$ & \\
\hline
\end{tabular}

This technique was repeated for the two NAPAP reduction scenarios (S1 and S4), the three sensitivity analyses, and the current damages scenario (for the Adirondack lakes only). The results of these estimations are presented in Table 3.3.

Table 3.3 shows the undiscounted WTP under eight simulations. As shown in Table 3.3 the change in value (between 1844 and 1989) associated with the average trout fishing trip is roughly $\$ 0.02$. The average angler would be willing to pay $\$ 0.02$ per trip for no damages from acidification (i.e, have 1844 conditions). Scenario S1 assumes that the reduction of acidification will be slow initially. As a result, water conditions will continue to deteriorate for the next several years. Under scenario $S 1$, the average angler would be willing to pay 89 cents per trip to have 1989 water quality in trout fishing lakes rather than the reduced water quality conditions forecasted for 2010. By 2030 , when the reductions in acidification assumed in scenario S1 
Forecasted Change in CPUE by Trout Species for Each Lake in Recreation Sample (Chapter 2)

\section{For Each Fish Specie Multiply Forecasted Change in CPUE Times the Hedonic Price Coefficient}

Sum the Results Over All Anglers and A11 Trips

Divide by the Total Number of Trips

The Result is the Average Willingness-to-pay per Trip e.g. Current Damages Scenario is $-\$ .02$

FIGURE 3.1. Steps in Calculating Marginal Willingness-to-pay from Changes in CPUE for the Hedonic Travel Cost Method

have improved water quality in trout fishing lakes, anglers receive a benefit of 22 cents per trip. Scenario 54 is a more aggressive control scenario. Under scenario S4, water quality in trout fishing lakes in the Northeast improves quickly. As a result, in 2010 anglers receive a benefit of 20 cents per trip. By 2030 this benefit has risen to 28 cents per trip. Under the sensitivity scenarios, the range of values generated by the hedonic travel cost model varies from a 33 cents per trip gain for a $50 \%$ reduction in acidification to a $\$ 7.86$ per trip loss if acidification were to grow by $30 \%$.

The random utility model is a discrete choice model of angler behavior. The parameters of the model are estimated using maximum likelihood methods. This model is used to simulate the decision about choice of site for each fishing trip. As with the hedonic travel cost model, the output is a change 
TABLE 3.3. Trout Angler Value Changes in the Northeast

Based on Hedonic Travel Cost Model

Scenario

Current Damages Analys is

Sensitivity Analyses

$50 \%$ Reduction

No Change

$30 \%$ Increase

NAPAP Reduction Scenarios

S1

S4
Price Per Trip

(1989 dollars)

$-0.02$

0.33

$-2.21$

$-7.86$

$\underline{2010} \underline{2030}$

$-0.89 \quad 0.22$

$\begin{array}{ll}0.20 & 0.28\end{array}$

in dollars per trip for an individual angler. The results can be aggregated across all anglers and all trips to derive a change in social welfare associated with changes in acidic deposition.

\subsection{RANDOM UTILITY MODEL}

The random utility model represents one of the most well-developed models of recreation behavior. Applied to recreation decisions, the model describes an individual's choice of which recreation site (i.e., lakes and rivers near an individual's home) to visit. The decision is based on the characteristics of the available sites and the cost of reaching the sites. The characteristics may include size, ease of access, and expected catch of fish. The costs include travel and time costs and, if relevant, site fee. The model assumes each site gives the individual some benefit, and that, having made the decision to take a trip, the individual visits the site with the highest utility. The uncertainty about which site an individual will choose is a random component in the model, capturing both unobserved characteristics of the site and unknown aspects of the individual's decision. 


\subsubsection{Background}

The model focuses on the single choice occasion (a trip): the individual can only choose one recreation site from among the available sites. Although individual anglers may take many trips during the recreation season, each choice is assumed to be independent of all other choices. This choice is modeled as a probability that the angler will choose a particular site. The benefit an individual receives from visiting a site is assumed to be a linear function of the characteristics of the site and the cost of reaching the site. Thus, the individual's choices of site characteristics are interpreted as probabilities rather than proportions of total choices (as in the hedonic mode1).

It is assumed that acidic deposition will reduce the catch rate (CPUE) at certain sites, which, in turn, will reduce the value associated with a trip to those sites. Thus, the maximum value the individual can attain for a given trip is likely to decline. How much value changes depends on the importance of the catch to the individual angler.

\subsubsection{Theoretical Structure}

Demand equations typically isolate the factors that influence how much of a particular good or service is purchased by a consumer. However, there are some goods that the consumer purchases singularly rather than in quantity. For such goods, the choice is not how much of the good to purchase, but rather which particular type, style, brand or model best fits the consumer's needs, or, in the choice of a recreation site, which bundle of attributes to select. A common characteristic of the two travel cost models presented here is that the choice to participate has already been made; the models predict which site will be chosen. The random utility model differs from other travel cost models in that it treats site selection as a discrete choice process.

Suppose, then, that an individual faces $m$ choices. According to the random utility model, there is an unobservable utility index associated with each choice which can be expressed as:

$$
u_{i}=v_{i}\left(x_{i}\right)+u_{i}
$$


where $x_{j}$ represents the observable attributes of the $i^{\text {th }}$ choice, and $u_{i}$ is a residual term that captures the unobserved random influences on the angler's utility level. Given the linear utility function in Equation (4), it can be shown that the probability that an individual chooses alternative $i$ is given by Equation (5):

$$
\operatorname{Prob}\left(U_{i}>U_{k} \text { for all } k=i\right)=\operatorname{Prob}\left(u_{i}-u_{k}>-\left(v_{i}-v_{k}\right)\right)
$$

Once the functional form of $V\left({ }^{\cdot}\right)$ has been specified and, with it, the joint probability distribution for the residuals, then a likelihood function can be determined and the parameters of $V\left({ }^{\circ}\right)$ can be estimated by any of various maximum likelihood methods.

If the decision process being modeled involves sequential choices, the model can be empirically estimated by "nesting" the choices in the framework of a decision tree. In that case there are several different solutions to the problem, but the one used most commonly in the literature is the nested logit model, attributed to McFadden $(1978,1981)$. This approach involves the sequential application of the conditional logit model. Nested logit formulations of the recreation decision tree allow the model to be applied to complex recreation valuation exercises. The decision trees are usually organized along the following lines.

The first choice a angler makes is the type of recreation, which for this analysis was fishing, boating, or swimming. If fishing is chosen, then the angler chooses the kind of waters to fish. The angler may choose a large lake, small lake, a river, or a stream. The angler then would choose the species of fish to be sought, e.g., catfish, bluegills, trout or steelhead. In this simple model, there are three nested choices. The first is what kind of recreation, the second is what kind of water, and the third is what species of fish. The choice of nesting order is entirely arbitrary.

\subsubsection{Application}

The parameters of the random utility model were estimated using the subset of individuals from the Recreational Fishing Survey who made at least one day-trip to a lake in Maine, New Hampshire, Vermont, or New York. (Individuals 
from Long Is 1 and were excluded as were trips to any of the Great Lakes.) The final data set included information on 530 individuals with 6,291 trips. The final specification was a non-nested model of day trips to lakes that included explanatory variables for price (travel and time cost), catch rate of targeted species, and characteristics believed to matter to individuals when making a fishing trip such as scenic view and lake size. Section B.2.1 in Appendix B gives a detailed description of the model specification.

The calculations used the expected catch rates for targeted species at each lake, as reported in the Freshwater Recreational Fishing Survey (each individual in the sample indicated which species, if any, was targeted on a particular trip). Catch rates were aggregated into four species groups: bass, trout, pike and panfish. For example, bass is the average catch rate of smal1mouth, largemouth, and other bass. Only the catch rate for the species group of which the targeted species is a member entered the utility function. For example, if an angler targeted smallmouth bass on a given trip, only the species group catch rate for bass was included in the utility function. (If a person did not indicate a targeted species, pan fish was used as the targeted species.) Estimating the demand for a site in a discrete choice framework requires identifying the sites not visited. In this analysis the parameters of the random utility model were estimated using data from the lake actually visited together with 11 randomly chosen lakes. The 11 randomly chosen lakes were selected to represent all the lakes that were not chosen. These 12 lakes constituted the angler's opportunity set. The parameter estimates for the random utility model are presented in Table 3.4 (see Appendix B, Table B.3, for variable definitions).

All coefficients were of the expected sign. The coefficients for price and time cost are negative, as expected, and were quite robust across alternative specifications. (For individuals with fixed work weeks, price is travel cost only, opportunity cost of time is entered as a separate variable called time cost.) Undoubtedly, an individual's probability of visiting a given site is lower, the higher the cost of reaching the site. The coefficients on the catch rates were all positive, indicating the better the catch, the higher the probability of a trip to the lake. The coefficients for the other site 


\begin{tabular}{lc}
$\begin{array}{l}\text { IABLE 3.4. } \\
\text { Variable }\end{array}$ & $\begin{array}{c}\text { Random Utility Model Maximum } \\
\text { Likel ihood Estimates }\end{array}$ \\
\cline { 1 - 1 } Price & -0.08 \\
Time & -0.54 \\
Size & 0.18 \\
Boat Ramp & 0.33 \\
View & 0.19 \\
Trout & 0.02 \\
Bass & 0.03 \\
Pike & 0.06 \\
Pan & 0.09 \\
Same State & 0.18 \\
No. of trips with \\
trout as target \\
Log Likel ihood
\end{tabular}

variables are all significantly different than zero. These values indicate that the probability of visiting a lake increases if the view is better, if the lake is larger, if a boat ramp is present (for anglers with a boat), and if the lake is in the same state in which the individual lives.

\subsubsection{Results}

The basic steps for calculating changes in welfare using the random utility model are given in Figure 3.2. The value of the change in trout catch rates due to changing acidification was calculated by predicting the change in expected WTP for the forecasted change in CPUE (derived from the physical data, see Chapter 2) associated with a particular deposition scenario. As 
with the hedonic mode1, this calculation was repeated for the current damages scenario, the two NAPAP reduction scenarios ( $S 1$ and $S 4$ ), and the three sensitivity analyses. The results of these estimations are presented in Table 3.5.

The random utility model estimates that the current damages from acidic deposition are approximately 12 cents per trip. That is, the average trout angler would be willing to pay an additional 12 cents per trip to all lakes undamaged (i.e., 1844 water quality). The two NAPAP control scenario estimates are similar to the hedonic travel cost results. For the S1 scenario, the average angler in 2010 is predicted to be willing to pay 80 cents to have water quality conditions comparable to 1989 conditions. The average trout angler in 2030 receives a benefit of 35 cents for the improved water quality forecast under $\mathrm{S1}$ for 2030 . In scenario $\mathrm{S4}$, the average angler receives a benefit of 48 cents per trip in 2010 due to the improved water quality conditions associated with greater deposition reduction levels. The benefit will increase to 61 cents per trip by 2030 . The sensitivity results indicate that the range of WTP values that the random utility model could produce is between $\$ 1.18$ per trip for a $50 \%$ reduction in deposition to -82 cents per trip if a $30 \%$ increase in deposition were to occur.

\subsection{SUMMARY}

One way to help gain perspective of these estimates is through comparison with previous work. Two previous studies have examined the impact of acidic deposition on recreational fishing. These two studies include Mullen and Menz (1985) and Morey and Shaw (1990). Menz and Mullen use a relatively simple travel cost model, often known as a gravity model, to find the economic losses associated with a $5 \%$ loss of the total Adirondack water body area. They find that the total social losses was about $\$ 1.07$ million annually. Morey and Shaw use a methodology known as the "share methodology." Morey and Shaw find that changes in CPUE of $5 \%, 25 \%$, and $50 \%$ generate corresponding we $1-$ fare gains of $\$ 4, \$ 9$, and $\$ 18$ respectively. Their estimates were developed for 607 anglers visiting four of seven sites in the Adirondacks. Their 
Forecasted change in CPUE by Trout Species for

Each Lake in Recreation Sample (Chapter 2)

Calculate the Next Best Utility Level Under the New CPUE Conditions for Each Angler for Each Trip Taken in 1989

Calculate Change in Utility Between Actual Trip Taken and Next Best Trip

Sum Changes in Utility Over all Anglers and All Trips

Divide by the Total Number of Trips to Find Average Willingness-to-pay per Trip (e.g., Current Damages is $-\$ .12$ )

FIGURE 3.2. Steps in Calculating Marginal Willingness-to-pay from Changes in CPUE for the Random Utility Model

approach was not designed to be part of a linked model or to be extrapolated to the population. Their results are not directly comparable to results reported here.

The \$/trip values, shown in Tables 3.4 and 3.5 , reflect the effects of changes in acid deposition levels on the economic value of individual fishing trips, as derived from the HTC and RUM models. To complete the analysis one must determine the effects of acid deposition and other factors on the total number of fishing trips which individuals take under the various scenarios. 
TABLE 3.5. Random Utility Model Trout Angler Value Changes in the Northeast

Scenario

Current Damages Analysis

\section{Sensitivity Analyses}

$50 \%$ Reduction

No Change

$30 \%$ Increase

NAPAP Reduction Scenarios

S1

S4
Price per Trip (1989 dollars)

$-0.12$

1.18

$-0.42$

$-0.82$

$\underline{2010}$

2030

$-0.80$

0.48

0.35

0.61

The total change in economic value for each scenario can then be determined by combining the information about the change in the value of individual trips and the change in the total number of trips. 


\subsection{THE PARTICIPATION MODEL}

This chapter describes the participation model that relates the number of fishing days to the catch per unit effort (CPUE), travel costs, and the demographic characteristics of the population. This analysis is needed to adjust the average per trip values developed in Chapter 3 . These adjustments were made to account for additional angling trips which would have been taken to the Adirondacks in 1989 under historical water conditions and the changes in the number of trips under the S1 and S4 conditions forecasted in 2010 and 2030. The econometric technique used to model this relationship was designed to improve the ability of conventional participation methods to address long-term trends and to provide a deeper level of insight than simple crosssectional analysis can provide. A cohort data set was used to produce combined time-series, cross-sectional estimates of participation in recreational fishing that properly account for dramatic demographic shifts in the composition of the population.

\subsection{BACKGROUND}

The participation model is based on how many fishing trips the individual takes that year. Trips are modeled as a linear relationship between trips, CPUE, and demographic characteristics. This intensity equation predicts the number of trips an individual will take. The advantage of the intensity equation is that the trip weight can be adjusted to reflect changing demographic characteristics in the population. (See Appendix $C$ for a detailed discussion of the participation model specification.)

\subsection{COHORT DATA DEVELOPMENT}

A cohort data set was used in this study to produce combined timeseries, cross-sectional estimates of the participation in recreational fishing. Conventional participation models are limited by their use of crosssectional data only. In general, estimates of any economic relationship based on cross-sectional data differ greatly from ones based on time-series data. The ideal analysis in cases such as this would follow the behavior of a set of 
randomly selected individuals over the course of many years. Historical estimates of the trends in outdoor participation have not used sets of data; therefore, the have not been able to untangle some inter-temporal issues important to understanding the role of demographic cohorts in policy analysis.

Unfortunately, the kinds of data required by the ideal analysis do not exist for recreational fishing. To overcome this limitation, an approach that combines independent cross-sections (i.e., following cohorts rather than individuals through time) to obtain a panel data set was employed. This analysis utilized data from two large general population surveys of outdoor recreation behavior: the 1980 and 1985 National Survey of Fishing, Hunting, and Wildlife-Associated Recreation (NSFHWR). These surveys are administered every 5 years by the U.S. Fish and Wildlife Service. By utilizing data from 2 years, both the intertemporal change in the composition of the population (the "baby boom") and the cross-sectional differences in angling opportunities were incorporated into the analysis. Ideally more than two data sets 5 years apart would have been available.

Specific "demographic" adjustments included in this study were median age, household income, urbanization, marital status, retirement status, student status, homemaker status, educational level, and race. Values related to these variables were projected to 2030 , based on projections available from the U.S. Census Bureau, the Social Security Administration, U.S. Department of Commerce Regional Projecting, and the Bureau of Labor Statistics.

\subsection{APPLICATION}

The participation model was used to forecast participation rates under five scenarios. These scenarios include the number of trips taken in 1989 in the Adirondacks under historical water quality conditions and the average number of fishing trips an individual will take in the years 2010 and 2030 under the conditions forecasted by $S 1$ and $S 4$. These numbers are dependent on forecast changes in CPUE due to acidic deposition as well as to demographic changes in the population. The parameters of a regression were estimated using data on age, income, whether an individual was black, married, retired, or lived in an urban area, average state-wide catch rates for bass and trout, 
and miles traveled for bass and trout sites. This regression allowed the number of days of fishing by the average individual to be forecast using data on changes in the independent variables in the regression. In this study, the demographic changes for 2 years, 2010 and 2030, were simulated using these parameters. Table 4.1 gives the 1989, 2010, and 2030 values of the independent variables. (See Appendix $C$ for sources of data).

As the table shows the effects of the baby boom are pronounced. The average age of the population will increase by nearly 9 years, and the percentage of the population retired will rise from $9.6 \%$ to $17.8 \%$, almost doubling in 40 years. Income also rises, and urbanization is predicted to increase slightly.

These changes have several effects on participation in recreational fishing. 01der people spend slightly more time fishing than younger people, until they retire. Once retired, people spend, on average, an additional 6 days per year fishing. Rising income also increases the number of days people spend fishing. Urbanization reduces the average number of days spent fishing as does being either married or black.

The final determinants of participation relate not to the demographic characteristics of the population but to their fishing opportunities and the cost of these opportunities. In these models, the fishing opportunities are the CPUEs the anglers encounter; the cost of the opportunities is the travel cost. The change in CPUE is the result of changing acidic deposition.

IABLE 4.1. Projected Mean Values of Selected Demographic Variables in 1989, 2010,2030

\begin{tabular}{llll}
\multicolumn{1}{c}{ Variable } & $\underline{1989}$ & $\underline{2010}$ & $\underline{2030}$ \\
\cline { 1 - 2 } $\begin{array}{l}\text { Age (years) } \\
\text { Real Income } \\
\text { (\$ thousands) }\end{array}$ & 33 & 38.9 & 41.8 \\
\% Urban & 16.5 & 20.4 & 23.5 \\
\% Married & & & \\
$\%$ Retired & $76.1 \%$ & $77.1 \%$ & $77.8 \%$ \\
$\%$ Black & $45.2 \%$ & $46.5 \%$ & $47.1 \%$ \\
& $9.6 \%$ & $11.2 \%$ & $17.8 \%$ \\
& $12.4 \%$ & $13.7 \%$ & $14.8 \%$
\end{tabular}


Changing acidic deposition should change the costs of fishing opportunities. In this application the relationship between cost and CPUE is modeled as a linear relationship. The change in CPUE, as forecast by the linkage model described in Chapter 2, is also used to simulate the participation equation. The change in CPUE by species (from the individual linkage models) is aggregated using their current percentage of a11 trout fishing trips as weights. This yields an average change in overall trout CPUE, which is used to simulate the participation model. The results were divided by the current (1989) figure for the average number of trips per person (calculated from the angling panel of the Aquatic Based Recreational Survey) to get the percentage change in the year of interest. Figure 4.1 shows the flow of these calculations. Table 4.2 shows the aggregate effect of the demographic, cost, and CPUE changes on the number of days people spend fishing. These numbers indicate the percentage change in the number of fishing trips an individual will take in the year.

In the current damages scenario, population is assumed to be unaffected by acidic deposition. As a result, the current damages scenario examines only changes in water chemistry across time. The current damages estimate represents the increase in angling participation that would occur in 1989 in the absence of acidification damages.

Finally, the changes in the number of days spent fishing had to be weighted to account for the changing population. Of course, for the current damages analysis the current (1989) population is still the appropriate base population. Table 4.3 gives the predicted percentage change in population from 1989 for the years 2010 and 2030.

\subsection{SUMMARY}

This chapter described the specification of the participation model and how it was used to forecast changes in demographic composition and changes in participation in recreational fishing in the years 2010 and 2030. In Chapter 5 , these numbers are used to adjust the weights from the recreational fishing sample to derive social welfare estimates associated with changes in acidic deposition. 
Forecasted change in CPUE by Trout
Species for Each Lake in
Recreation Sample
Forecasted Change

in Demographic

Characteristics

Calculate New Predicted Number of Days Fishing

Calculate Percentage Change in Number of Days Fishing

FIGURE 4.1. Steps in Calculating the Change in Participation as a Result of Changes in CPUE and Changes in Population Demographics

TABLE 4.2. Projected Change in the Number of Days
Spent Fishing

Current Damages Scenario

\% Change $\quad 8.5$

NAPAP Scenarios

$\underline{2010}$

$\underline{2030}$

$\%$ Change $\mathrm{S} 1$

0.9

12.5

\% Change 54

1.0

12.5

(a) - 1989 is the base year. 
TABLE 4.3. Projected Population Growth
in 2010 and 2030 (a)

$\begin{array}{lcc}\text { \% Change } & \frac{2010}{22} & \frac{2030}{44}\end{array}$

(a) - 1989 is the base year. 


\subsection{RESULTS}

This chapter integrates the results of Chapters 3 and 4 to produce the final results of the analysis. The travel cost models of Chapter 3 produced two estimates of changes in welfare for each day of fishing by an individual angler. The participation model estimates the number of fishing days that will occur as a result of changes in catch rates attributable to changes in deposition and changes in the demographic composition and size of the population in 2010 and 2030.

\subsection{SOCIAL WELFARE CALCULATIONS}

Social welfare values can be derived from the values presented in Chapters 3 and 4 using the following procedure. The individual welfare is estimated by multiplying the average willingness-to-pay (WTP) per trip times the average number of trips per individual times the total number of individuals in the population, as indicated in the following equation:

$$
\text { trips/person * total population * \$/trip = total \$ }
$$

The calculations were made using the average percentage change in trips per person and the percentage change in population compared to 1989 figures times the 1989 figures in each case. The dollar per trip values are the outputs of the travel cost models. The changes in the other two variables were calculated in Chapter 4. Equation (2) shows this calculation.

$$
\begin{aligned}
& \text { change in trips/person * }(1989-\text { trips/person }) * \text { change } \\
& \text { in population * }(1989 \text { population }) * \$ / \text { trip }=\text { total } \$
\end{aligned}
$$

\subsection{RESULTS}

Table 5.1 gives the results from various stages of the analysis (documented in previous chapters) together with the final welfare results for the various scenarios and the two travel cost models. These numbers are reported 
TABLE 5.1. Calculation of Social Welfare Estimates

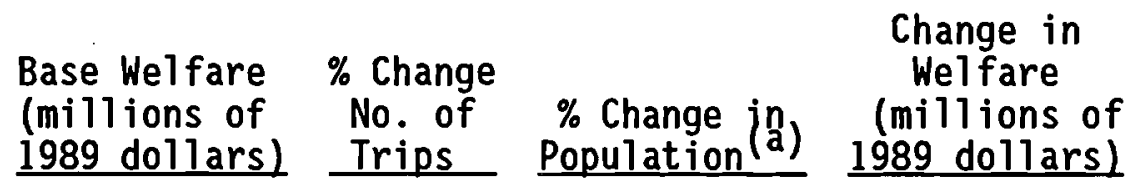

Current Damages

(Adirondack Park)

HTCM

RUM

$-0.25$

8.5

8.5

$-0.2$

$-1.7$

Sensitivity

Analyses (2030)

HTC $\quad-50 \%$

No change

$+30 \%$

4.2

$-27.5$

$-97.7$

RUM $\quad-50 \%$

No change

$+30 \%$

14.7

$-5.3$

$-10.3$

NAPAP Reduction

S1

HTC 2010

2030

$-11.1$

0.9

2.8

12.5

22

$-13.7$

$-1.0$

0.9

22

3.5

RUM 2010

4.4

12.5

$-1.2$

2030

S4

HTC 2010

$2.5 \quad 1.0$

22

44

3.0

3.5

12.5

4.4

2010
2030

$\begin{array}{ll}6.0 & 1.0\end{array}$

7.7

12.5

22

7.4

44

9.7

(a) 1989 population of four states (ME, NH, NY, VT) $=13,043,635$ 
as changes in value from current levels. They are given in 1989 dollars and represent the annual damages that will occur under each deposition scenario.

The results in the final column of Table 5.1 are those reported in the NAPAP Integrated Assessment (IA). The first column shows the base welfare. The base welfare is the per-trip welfare based upon 1989 demographic characteristics and participation in recreational fishing. The second column shows the change in the participation that is forecast to result from changes in demographics and the effects of acidification in the years 2010 and 2030 . For example, under the hedonic travel cost model the fraction of visitor days (trips) that will occur in 2010 is 1.1284 times (12.84\%) as many as in the 1989 sample. The next number is the percentage increase in the population in that year. Finally, the estimated total value for the population weights is given.

\subsubsection{Current Damages Scenario Results}

The results of the current damages scenario shown in Table 5.1 indicate the total annual damages to recreational trout fishing in New York's Adirondack Park due to changes in levels of acidification from 1844 to 1989. These estimates, $\$ 0.27$ million (HTCM) and $\$ 1.75$ million (RUM), are comparable to results from previous studies, al though the physical effects simulated in previous studies are far more severe than actual changes in water quality would indicate. (See Mullen and Menz 1985; and Violette 1985).

\subsubsection{Sensitivity Analysis Results}

The results of the sensitivity analysis for the two travel cost models are given in Table 5.1. Simulating a 50\% decrease from current levels of sulfur deposition resulted in estimates of economic benefits of $\$ 4.2$ million (HTCM) and $\$ 14.7$ million (RUM) annually for the two models. These numbers indicate the increased value to recreational trout anglers of this level of sulfur reduction. If sulfur emissions continue at current levels, the estimated damages to recreational anglers will be $\$ 5.3$ million (RUM) and $\$ 27.5$ million (HTCM) annually. A $30 \%$ increase in current deposition will result in additional recreational fishing losses of $\$ 10.3$ million (RUM) and $\$ 97.7 \mathrm{mil-}$ lion (HTCM) annually. 
The differences in the values for the two travel cost models for the $50 \%$ reduction and no-change scenarios were expected. These differences could be because of the models' different treatments of individual behavior and the different functional forms that were used to fit the models to the recreational fishing data. The difference for the third scenario, the $30 \%$ increase in sulfur deposition, was larger than expected. There are several factors that may contribute to this result. First, WTP was more sensitive in the hedonic model to increases in acidic stress (ASI), and resulting decreases in catch rate (CPUE). Second, the hedonic model was also more sensitive to the effects of regional differences in ASI and CPUE changes on angler welfare. Third, the estimates for the $30 \%$ increase scenario were driven by a large increase in ASI, resulting in a large decrease in angler WTP, especially in three Adirondack counties. These increases in deposition resulted in nonmarginal shifts in CPUE in some counties. Although these were simulated in both models, the hedonic model was more sensitive to the magnitude and distribution of ASI changes because this application was focused on marginal changes in CPUE. By its nature the random utility model addresses both marginal and non-marginal changes simultaneously and so incorporated a wider range of behavior than the hedonic model.

\subsubsection{NAPAP Scenario Results}

The economic values for the two NAPAP reduction scenarios, S1 and S4, are based on changes in acidification levels (ASIs) compared to current (1989) conditions. For $\mathrm{Sl}$, both travel cost models predict economic losses (negative benefits) to recreational trout fishing in 2010. However, by 2030 the models predict that the scenario will result in benefits. The estimated value of the damages in 2010 is $\$ 1.23$ million (HTCM) and $\$ 13.7$ million (RUM) annually. The initial loss in value reflects the fact that the slower reduction in deposition levels will cause continued acidification over the next 20 years. However, by 2030 reduced deposition levels will result in small increases in welfare. Under S4, both travel cost models indicate improvements in welfare. A large part of the benefit will be achieved by 2010. Although the random 
utility model predicts higher values, welfare gains are modest, less than $\$ 10$ million, in both models. Both models predict an additional improvement of approximately $\$ 2$ million per year in 2030 .

\subsubsection{Differences in Model Estimates}

The two models produce damage and benefit estimates that are of the same sign. The differences in the magnitude of the estimates reflect two differences in modeling strategy. The first difference is the hedonic model's sensitivity to local variations in WTP. The hedonic travel cost model estimates a set of individualized parameters for each county. The random utility model averages over the entire study area. The second difference is the treatment of individual trout species. In the hedonic travel cost model, each trout species also has its own WTP parameter. The random utility model lumps the trout species together. The result of these differences is that the hedonic travel cost model has considerably more parameters, and so has the potential for greater volatility in its estimates.

With one notable exception, the hedonic travel cost and the random utility model estimates are remarkably close. The exception is the $30 \%$ increase scenario. Under this scenario, the hedonic travel cost model estimates a loss of $\$ 97.7$ million while the random utility model shows a loss of only $\$ 10.3$ million. The cause of this difference turns out to be large parameters on the rainbow trout term for several northeastern counties in New York coupled with non-marginal changes in CPUE. One explanation for the size of these parameters is that these counties are pinned between Canada and Vermont. Residents of these counties face a steep marginal price for increases in CPUE for some kinds of trout fishing. The local sensitivity of this model captures an effect, real or not, which is not present in the random utility model. The other estimates are based on scenarios that, when simulated, cause marginal changes in CPUE. These welfare estimates are relatively close. Each is positive and most are within $50 \%$ of one another.

These estimates should not be considered upper or lower bounds. The estimates are two point estimates of the economic effects of changing acidic deposition conditions. Little evidence suggests that either model produces higher or lower values than the other. What can be stated with some 
confidence is that the order of magnitude of the damages, particularly for the current damages, S1, and S4 scenarios, is consistent across the findings of the hedonic travel cost model and the random utility model.

\subsection{LIMITATIONS}

The following are several limitations to this analysis.

1. Both the biological and economic assessments were based on samples, so the precise location of lakes that have lost fish cannot be determined. Because of this, impacts were spread evenly across the study area and estimates were based on average impacts. This approach may underestimate the total welfare losses for specific lakes.

2. The analysis is limited to impacts on recreational fishing in four Northeastern states. However, the Northeast is not the only region in the country that would likely benefit from reduced emissions.

3. These estimates do not include the value of damages due to reductions in the populations of non-trout species or of losses associated with fishing in streams. Since there are acidic effects in streams and on nontrout species in the Northeast the economic impacts documented in this report are underestimates of the total impacts in the Northeast.

4. These estimates may understate the damages to brook trout anglers. Because there were limited data for brook trout fishing conditions in acidified lakes, it was not possible to simulate increases in the WTP of brook trout anglers for improved water quality conditions. (a) As a result, the total damages presented in the analysis are likely to be underestimates of the total economic damages from acidic deposition.

5. The analysis assumed that the sensitivity is the same for small and large lakes so that small lakes (less than 4 hectares in area) could be included. However, the size of a lake can influence the effects of changes in water chemistry on fish populations. Furthermore, for a number of reasons, small lakes in the Adirondacks tend to be more sensitive than large lakes to changes in deposition. The impact of excluding lakes less than 4 hectares is likely to produce an underestimate of true total damages.

6. The distribution of ASIs in lakes used to develop the linkage model (i.e., lakes that were in both the ELS and ABRS) is not the same as the distribution of lakes in the ELS data set as a whole. The mean ASI for

(a) Only two of the brook trout anglers in the recreational fishing sample caught brook trout in lakes where the ASI was greater than zero (no threat to brook trout), and the acidic stress in these lakes was not high. 
lakes in the intersection data set is lower than the mean for the ELS data set. It is unknown whether these differences fall with normal sampling effects or represent real differences. The effect of these differences on the estimates is uncertain.

7. Anglers from New York City were excluded from the analysis due to sample size considerations. This causes the reported estimates to understate the total effects, although the scale of the effect may be small if there are few anglers in New York City.

8. The estimates are based on anglers' WTP for improved water quality. They do not reflect WTP for non-use values. However, people who do not fish may nevertheless attach an intrinsic value to the loss of fish. The total social value associated with improvements, which includes both use and non-use effects, is likely to be larger than the reported use effects alone.

9. The analysis was limited to day trips to lakes and ponds. Longer trips and stream and river fishing were not included in the analysis. 
-

. 


\subsection{REFERENCES}

Bockstae1, N. E., K. E. McConne11, and I. E. Strand. 1988. Benefits from Improvements in Chesapeake Bay Water Quality. Report for the U.S.

Environmental Protection Agency under Cooperative Agreement CR-811043-01-1 with the University of Maryland, College Park, Maryland.

Brown, G. and R. Mendelsohn. 1984. "The Hedonic Travel Cost Method." Review of Economic Statistics 66:427-433.

Deaton, A. 1985. "Panel Data from a Time Series of Cross-Sections." Journal for Econometrics 30:109-126.

Hausman, J. A. and D. A. Wise. 1978. "A Conditional Probit Model for Qualitative Choice: Discrete Decisions Recognizing Interdependence and Heterogeneous Preferences." Econometrica 46:403-426.

McFadden, D. 1978. "Modelling the Choice of Residential Location." In Spatial Interaction Theory and Planning Models. Anders Karlquist, Lars Lundavist, Folke Snickars, and Jorgen W. Weibull (eds.), North-Holl and Publishing Company, New York.

McFadden, D. 1981. "Econometric Models of Probabilistic Choice." In Structural Analysis of Discrete Data. C. F. Manski and D. McFadden (eds.), MIT Press, Cambridge, Massachusetts.

Mendelsohn, R., T. Moore and E. Whitelaw. 1984. Economic Valuation of Potential Losses of Fish Population in the Swan River Drainage. Prepared by Eco-Northwest for the Montana Department of Fish, Wildlife, and Parks.

Morey, E. R., and W. D. Shaw. 1990. "An Economic Model to Assess the Impact of Acid Rain: A Characteristics Approach to Estimating the Demand for and Benefits from Recreational Fishing." In Advances in Applied Microeconomic Theory, Vol. 5. Link and Smith, eds. JAI Press, Greenwich, Connecticut.

Mullen, J. K. and F. C. Menz. 1985. "The Effect of Acidification Damages on the Economic Value of the Adirondack Fishery to New York Anglers." American Journal of Agricultural Economics, 67:112-119.

Shankle, S. A., J. E. Englin, W. H. Monroe, D. M. Beck, M. F. Casinelli, H. Saunders, S. E. Grover. 1990. Freshwater-Based Recreation in the Upper Northeast: Data Collection Documentation. PNL-7524. Pacific Northwest Laboratory, Richland, WA.

Violette, D. M. 1986. A Model Estimating the Economic Impacts of Current Levels of Acidification on Recreational Fishing in the Adirondack Mountains. EPA Report No. 230-12-86-021, US. Environmental Protection Agency, Office of Policy Planning and Evaluation. Washington, D.C. 20460. 


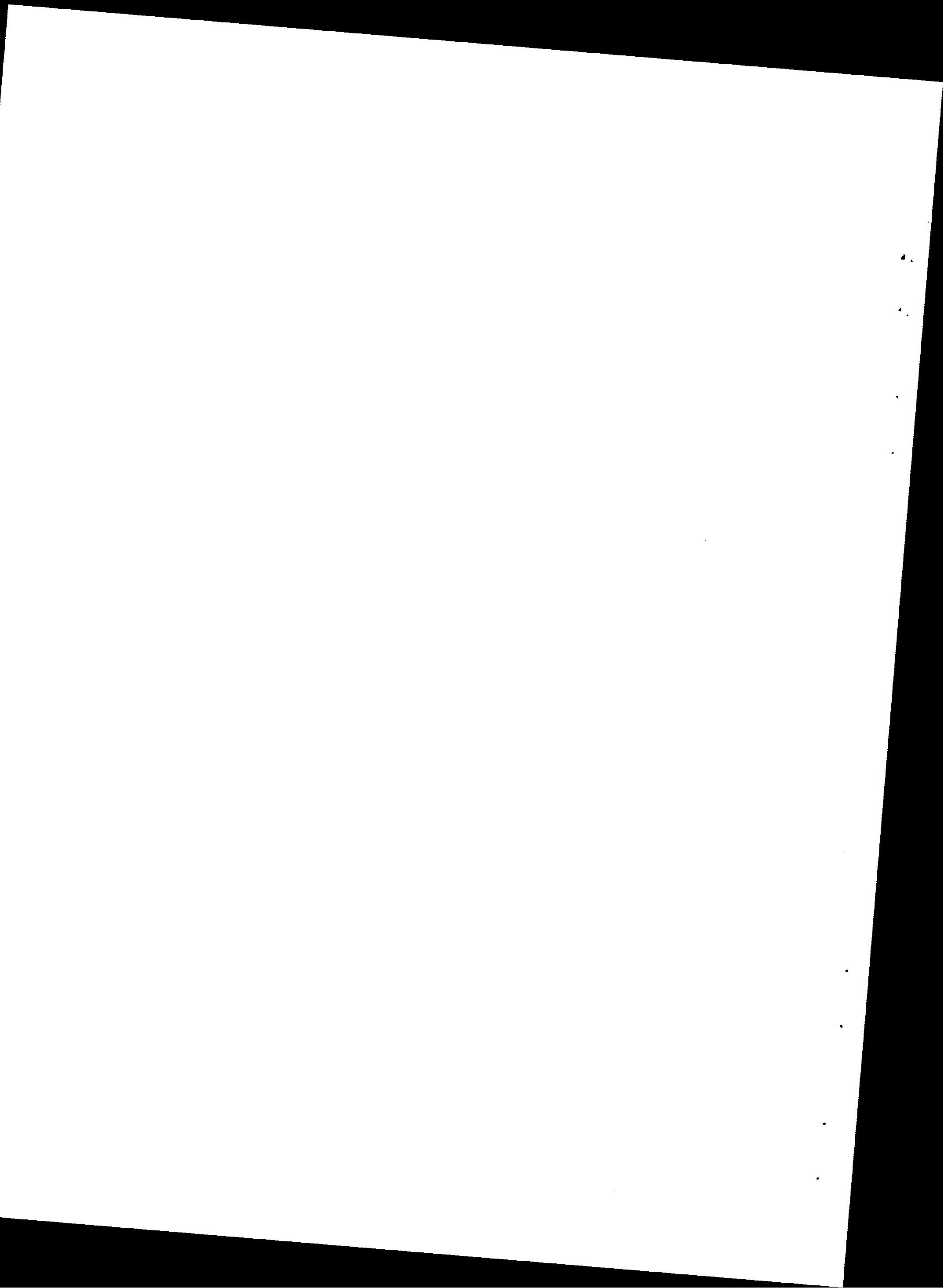




\section{APPENDIX A}

\section{CPUE ANALYSIS RESULTS}




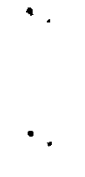




\section{APPENDIX A}

\section{COST PER UNIT EFFECT ANALYSIS RESULTS}

This appendix presents results of the cost per unit effect (CPUE) analysis. It also gives model specifications used in linking the biological and economic data.

\section{A.1 DATA CALCULATIONS}

Toxicity models developed by the Aquatics Effects Research Program (AERP) were used to calculate current acidic stress levels for lakes in the intersection data set described in Section 2.1. For the rest of the lakes visited in the Recreational Fishing Survey, initial Acidic Stress Indexes (ASIs) had to be estimated using forecasting models. Direct/Delayed Response Project (DDRP) data provided information on changes in data associated with each of the scenarios considered in this study. These data were used in conjunction with the regression results of the forecasting models to predict percentage changes in data for each of the deposition scenarios.

\section{A.1.1 Toxicity Models}

Toxicity models predict conditional mortality rates for fish based on measured fish responses in laboratory bioassays. These regression models are used to estimate the acidity-related stress on fish associated with measured (or projected) levels of $\mathrm{pH}$, inorganic monomeric aluminum, and calcium in the field. The models are calibrated using controlled experimental data.

Fish species vary in their sensitivity to acid-based chemistry. In order to cover the range of acid sensitivity of species in the sample lakes, three models were used, for tolerant, intermediate, and sensitive species. Each index in based on experimental survival rates of fish fry of representative species under varying water chemistry conditions. The tolerant index is based on brook trout fry survival; the intermediate is based on smallmouth bass fry survival, and the sensitive index on rainbow trout fry survival. The specifications for these models are given by Equations (A.1) through (A.3). 


$$
\begin{aligned}
& \mathrm{ASI}_{\mathbf{i}}=\frac{100}{1+\mathrm{e}^{-23.49+5.35 * \mathrm{pH}-0.00297 * \mathrm{Ca}-0.00193 * \mathrm{~A} 1}} \\
& \mathrm{ASI}_{S}=\frac{100}{1+\mathrm{e}^{-8.90+1.56 * \mathrm{pH}-0.00409 * \mathrm{Ca}-0.0704 * \mathrm{~A} 1}} \\
& \operatorname{ASI}_{\mathrm{t}} \\
& 100
\end{aligned}
$$

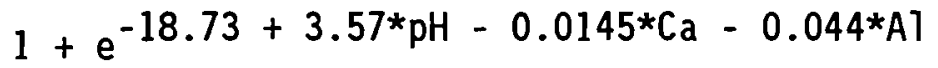

Using Eastern Lakes Survey (ELS) data on chemical and watershed characteristics, these indices were estimated to determine current levels of stress for all lakes in the intersection data sets described in Section 2.1. Table A.1 shows the distribution of ASIs in the intersection data set. As can be seen, there was some fishing in lakes under the maximum degree of stress. However, fishing in these lakes tended to be for species other than trout species.

Since ELS data provided the necessary chemical and watershed characteristics, calculating ASIs for lakes in the intersection data set was straightforward. Unfortunately, the sample is small relative to all lakes available for fishing in the upper Northeast. Therefore, the initial ASIs and the changes in ASIs had to be forecasted for lakes with incomplete information. Forecasting models were developed for this purpose.

TABLE A.1. ASI Statistics for Intersection Data Set

\begin{tabular}{lccc}
\multicolumn{1}{c}{ ASI } & Mean & Minimum & Maximum \\
\cline { 2 - 3 } Sensitive & 15.65 & 0.0 & $100.0^{(\mathrm{a})}$ \\
Intermediate & 3.17 & 0.0 & 100.0 \\
Tolerant & 0.12 & 0.0 & 50.4
\end{tabular}

(a) 100 indicates that $100 \%$ of fish fry died in laboratory experiments with the same water chemistry. 


\section{A.1.2 ASI Forecasting Models}

The purpose of the model specification was to use information about the watershed, lake size, geographic location, water quality, and angling activity to predict ASI. Essentially, the notion was to proxy the underlying water chemistry models with characteristics that could be observed by lay people.

These models were constructed using the entire intersection data set. The explanatory variables used in this analysis included only those variables that were present in the ABRS data set. This allows the models to be used to forecast the ASI starting indices using the ABRS data. No model was constructed for the tolerant ASI class because only three lakes had trips with brook trout as the target and non-zero tolerant ASI indices. The highest ASI in a visited lake was 0.63 , essentially zero.

The final sensitive regression was fit with a linear functional form; the final intermediate regression was fit using a semi-logarithmic functional form. Based upon the findings of AERP, three basic kinds of physical characteristics are expected to be correlated with ASI. These include the vegetation in the watershed, the size of the water body, and the geographic location of the water body. The AERP models contain precise measures of these variables. Unfortunately, these measurements are very expensive to obtain. The Freshwater Recreational Fishing Survey contains information about lakes and ponds that are observable to the layman. These variables are proxies for the underlying physical relationships that govern the level of ASI in a lake or pond. Table A.2 presents the regression results for the two specifications.

The two forecasting regressions predict sensitive and intermediate ASI levels as a function of four basic kinds of variables. These variables include weeds, watershed, geographic location and kinds of recreational activities taking place at the site. All of the independent variables are taken from the Freshwater Recreational Fishing Survey. The weed variables are simply dummy variables based upon a five-level Likert scale. A value of 1 is no weeds, with a value of 5 indicating many weeds. The watershed variables are the percentage of shoreline of one type. For example, if "Pine Trees" takes on a value of 10 , the shoreline around the lake is $10 \%$ Pine Trees. The launch variable indicates the presence or absence of a boat launch. Locational 
variables are dummy variables that identify the state and size of the body of water. Finally, the activity variables are dummy variables that reflect what activities took place at the site on that trip.

The coefficients on each variable indicate the influence that variable has on the ASI for that lake. For example, having a boat launch is predicted to decrease the sensitive ASI by 13.19. Since the intermediate ASI is in logarithmic form it's interpretation is less straightforward. The launch variable is predicted to reduce the $\log$ of the intermediate ASI by -0.23 . The equations fit fairly well with R-squares over 0.80 .

The first step in the analysis was to forecast the beginning sensitive and intermediate ASI for each lake visited in the Recreational Fishing Survey. For those lakes with a negative predicted ASI, the ASI was reset to zero. A11 of the tolerant ASIs had a beginning value of zero. Table A.3 shows the base1 ine forecasted ASI indices for the full angler data.

DDRP biological models provide data on forecasted ASI shifts for each of the deposition scenarios considered in this study. These estimates, given in Tables A.4 and A.5, were calculated for a random sample of lakes in the ELS. Since DDRP lakes are a random sample, the changes in ASI can be used to describe the population of lakes in the Northeastern states. The current damages scenario, Table A.4, is limited to DDRP lakes in the Adirondack Park.

The other scenarios, reported in Table A.5, are calculated including all DDRP lakes in New York, New Hampshire, Vermont and Maine. The tables show the beginning ASI class (predicted ASI in 1989), the number of DDRP lakes in that class, and the change in ASI for each class of lakes for 2010 and 2030 . As can be seen in the tables, the DDRP sample of lakes did not completely cover all classifications of each beginning ASI. In these cases the ASI value used in the simulations was estimated by averaging the values from the ASI class above and below the missing value. For example, there are no DDRP lakes with a beginning intermediate ASI of 81-90. This value would be the average of the 71-80 and 90-100 values. 
TABLE A.2. Sensitive and Intermediate Acidic Stress Index (ASI) Forecasting Estimations: Regression Results (t statistics in parentheses)

Variable

Constant

Weeds

$$
\begin{aligned}
& \text { Leve } 1=1 \\
& \text { Leve } 1=2 \\
& \text { Leve } 1=4 \\
& \text { Leve }=5
\end{aligned}
$$

Watershed

Deciduous Trees

Pine Trees

Agricultural

Meadows

Water Visibility

Launch

\section{Location}

New Hampshire

Vermont

Maine

\begin{tabular}{|c|c|}
\hline $\begin{array}{l}\text { Sensitive } \\
\text { Coefficients }\end{array}$ & $\begin{array}{l}\text { Intermedia } \\
\text { Coefficie } \\
\end{array}$ \\
\hline $\begin{array}{l}15.29^{(b)} \\
(7.02)\end{array}$ & $\begin{array}{l}-2.06^{(b)} \\
(-4.91)\end{array}$ \\
\hline
\end{tabular}

New York Pond

Maine Pond

New Hampshire Pond

$$
\begin{aligned}
& -4.1^{(b)} \\
& (-3.59) \\
& -1.19 \\
& (-0.78) \\
& -13.48^{(b)} \\
& (-7.78) \\
& -6.19^{(b)} \\
& (-4.36)
\end{aligned}
$$$$
0.16^{(b)}
$$$$
\text { (8.47) }
$$$$
\text { 2. } 90 \mathrm{e}-02
$$$$
\text { (1.40) }
$$$$
\text { 9.02e-04 }
$$$$
\text { (2.29e-02) }
$$$$
-0.18^{(\mathrm{b})}
$$$$
(-2.56)
$$$$
-0.56(b)
$$$$
(-8.52)
$$$$
-13.19 \text { (b) }
$$$$
(-11.63)
$$

$10.69^{(b)}$

(7.01)

$6.20^{(b)}$

(3.45)

$6.10^{(b)}$

$(4.16)(b)$

(4.84)

$-6.92^{(b)}$

$(-3.56)$

$10.55^{(b)}$

(5.21)

$$
\begin{gathered}
-0.86^{(b)} \\
(-7.37) \\
7.63 \mathrm{e}-02 \\
(0.47) \\
-0.89(\mathrm{~b}) \\
(-3.43) \\
0.26
\end{gathered}
$$

$$
\begin{gathered}
2.26 \mathrm{e}-02^{(b)} \\
(6.26) \\
4.15 \mathrm{e}-03 \\
(1.18) \\
0.55(\mathrm{~b}) \\
(12.47) \\
-6.21 \mathrm{e} 02^{(b)} \\
(-6.13) \\
-7.34 \mathrm{e}-02^{(b)} \\
(-10.02)(\mathrm{c}) \\
-0.23^{(c)} \\
(-1.71)
\end{gathered}
$$

$$
\begin{gathered}
0.52^{(b)} \\
(2.38) \\
-0.68^{(b)} \\
(-2.53) \\
-0.49^{(b)} \\
(-2.34) \\
-0.83(b) \\
(-2.77) \\
-9.43 e-02 \\
(0.49) \\
2.22^{(b)} \\
(9.56)
\end{gathered}
$$


TABLE A.2. (contd)

Variable

Sensitive

Coefficients

Intermediate ${ }^{(a)}$

Coefficients

Trip Activities

Fishing

$-8.42 e-02^{(b)}$

$-1.08 \mathrm{e}-02^{(b)}$

Swimming

$(-9.12)$

(17.65)

Boating

$8.76 \mathrm{e}-02^{(b)}$

(2.19)

$(-11.17)$

$7.35 \mathrm{e}-02^{(b)}$

(14.29)

$9.99 \mathrm{e}-03^{(b)}$

(2.18)

Observations

R-squared

1208

0.81

Corrected R-squared

0.80

986

0.84

0.84

(a) Dependent variable in the natural logarithm of intermediate ASI.

(b) Significant at the 0.05 level.

(c) Significant at the 0.10 level.

TABLE A.3. Basel ine Acidic Stress Index (ASI) Indices for all Aquatic Based Recreation Survey (ABRS) Lakes

$\begin{array}{lccc}\text { Index } & \underline{\text { Mean }} & \text { Minimum } & \text { Maximum } \\ \text { Sensitive } & 0.52 & 0.21 & 17.50 \\ \text { Intermediate } & 0.24 & 0.21 & 7.67 \\ \text { Tolerant } & 0.00 & 0.00 & 0.00\end{array}$

TABLE A.4. Direct/Delayed Response Project (DDRP)

Acidic Stress Index (ASI) Shifts

Current Damages Scenario

\section{ASI}

Sensitive ASI

Intermediate ASI

Tolerant ASI
0.25

33.23

69.03
1988 ASI

4.2

42.15

68.07

Delta ASI

$-4.0$

$-8.92$

$+1.04$ 
IABLE A.5. National Acidic Precipitation Assessment Program (NAPAP) Scenarios

\section{Change in Sensitive ASI -. Scenario S1}

Beginning

ASI Class

\begin{tabular}{|c|c|c|}
\hline Number of Lakes & 2010 & 2030 \\
\hline 30 & 0.1225 & 0.114 \\
\hline 21 & 0.1037 & -.3447 \\
\hline 10 & 0.3853 & -2.0614 \\
\hline 7 & 0.5149 & -5.2554 \\
\hline 5 & 2.7687 & -6.7260 \\
\hline 6 & 8.0272 & -14.0612 \\
\hline 2 & 8.6170 & -15.6626 \\
\hline 1 & 15.4367 & -8.8246 \\
\hline 1 & 0.6716 & -18.2094 \\
\hline 8 & -2.6269 & -19.8178 \\
\hline
\end{tabular}

\section{Change in Sensitive ASI -- Scenario S4}

\begin{tabular}{|c|c|c|c|}
\hline $\begin{array}{l}\text { Beginning } \\
\text { ASI Class }\end{array}$ & Number of Lakes & 2010 & 2030 \\
\hline $0-10$ & 30 & 0.076 & 0.1165 \\
\hline $11-20$ & 21 & -.411 & -.4710 \\
\hline $21-30$ & 10 & -3.5276 & -3.3496 \\
\hline $31-40$ & 7 & -5.077 & -6.3973 \\
\hline $41-50$ & 5 & -7.0982 & -8.8002 \\
\hline $51-60$ & 6 & -13.3029 & -17.3255 \\
\hline $61-70$ & 2 & -16.7841 & -20.9387 \\
\hline $71-80$ & 1 & -17.9102 & -21.7842 \\
\hline $81-90$ & 1 & -24.2851 & -26.1461 \\
\hline $91-100$ & 8 & -25.9198 & -29.8499 \\
\hline
\end{tabular}


IABLE A.5. (contd)

Change in Intermediate ASI -- Scenario S1

\begin{tabular}{|c|c|c|c|}
\hline $\begin{array}{l}\text { Beginning } \\
\text { ASI Class }\end{array}$ & Number of Lakes & 2010 & 2030 \\
\hline $0-10$ & 74 & 0.0605 & -0.1570 \\
\hline $11-20$ & 6 & 16.5282 & -6.8785 \\
\hline $21-30$ & 1 & 10.7915 & -14.4081 \\
\hline $31-40$ & 1 & 39.5780 & -3.1981 \\
\hline $41-50$ & $\ldots(a)$ & -- & $\ldots$ \\
\hline $51-60$ & -- & --- & -.- \\
\hline $61-70$ & 1 & 3.9175 & -31.1970 \\
\hline $71-80$ & 1 & -32.4262 & -76.0360 \\
\hline $81-90$ & $\cdots$ & -- & -.. \\
\hline $91-100$ & 7 & -0.6599 & -28.6385 \\
\hline
\end{tabular}

Change in Intermediate ASI -- Scenario S4

\begin{tabular}{|c|c|c|c|}
\hline $\begin{array}{l}\text { Beginning } \\
\text { ASI Class }\end{array}$ & Number of Lakes & 2010 & 2030 \\
\hline $0-10$ & 74 & -.1573 & -.1906 \\
\hline $11-20$ & 6 & -6.1309 & -9.4034 \\
\hline $21-30$ & 1 & -12.4779 & -16.5147 \\
\hline $31-40$ & 1 & -12.2509 & -20.2665 \\
\hline $41-50$ & $\ldots$ & -- & -- \\
\hline $51-60$ & -.. & $\ldots$ & $\ldots$ \\
\hline $61-70$ & 1 & -32.7219 & -37.9194 \\
\hline $71-80$ & 1 & -71.1236 & -77.3019 \\
\hline $81-90$ & $\ldots$ & -- &.- \\
\hline $91-100$ & 7 & -39.6595 & -46.3703 \\
\hline
\end{tabular}

(a) -.- means no data available. 
TABLE A.5. (contd)

\section{Change in Tolerant ASI _- Scenario S1}

\begin{tabular}{|c|c|c|c|}
\hline $\begin{array}{l}\text { Beginning } \\
\text { ASI Class }\end{array}$ & Number of Lakes & 2010 & 2030 \\
\hline $0-10$ & 85 & 0.0519 & -0.0557 \\
\hline $11-20$ & -- & -- & -.- \\
\hline $21-30$ & 1 & -3.6613 & -22.8393 \\
\hline $31-40$ & 1 & 20.5121 & -6.3552 \\
\hline $41-50$ & $\ldots$ & -.- & -.. \\
\hline $51-60$ & 1 & .2067 & -53.6177 \\
\hline $61-70$ & -- & -- & -- \\
\hline $71-80$ & -. & -- & -.. \\
\hline $81-90$ & 1 & -3.3095 & -70.1222 \\
\hline $91-100$ & 2 & -3.2804 & -44.2733 \\
\hline
\end{tabular}

Change in Tolerant ASI -. Scenario S4

\begin{tabular}{|c|c|c|c|}
\hline $\begin{array}{l}\text { Beginning } \\
\text { ASI Class }\end{array}$ & Number of Lakes & 2010 & 2030 \\
\hline $0-10$ & 85 & -0.0472 & -0.0648 \\
\hline $11-20$ &.- & -- &.- \\
\hline $21-30$ & 1 & -20.1195 & -23.334 \\
\hline $31-40$ & 1 & -15.8315 & -17.9549 \\
\hline $41-50$ & $\ldots$ & -- &.- \\
\hline $51-60$ & 1 & -45.5907 & -56.9102 \\
\hline $61-70$ & -- &.- & -- \\
\hline $71-80$ & -- & -- & $-\cdot$ \\
\hline $81-90$ & 1 & -62.9912 & -81.4575 \\
\hline $91-100$ & 2 & -51.1483 & -61.8101 \\
\hline
\end{tabular}


TABLE A.5. (contd)

\section{SENSITIVITY ANALYSES}

Change in Sensitive ASI

\begin{tabular}{|c|c|c|c|c|}
\hline $\begin{array}{l}\text { Beginning } \\
\text { ASI Class } \\
\end{array}$ & Number of Lakes & $-50 \%$ & $0 \%$ & $+30 \%$ \\
\hline $0-10$ & 30 & 0.1143 & 0.2115 & 0.2953 \\
\hline $11-20$ & 21 & -0.6922 & 0.3161 & 2.0507 \\
\hline $21-30$ & 10 & -5.2331 & 1.2664 & 3.9820 \\
\hline $31-40$ & 7 & -7.5686 & 2.5251 & 34.0317 \\
\hline $41-50$ & 5 & -10.6464 & 7.6718 & 43.6418 \\
\hline $51-60$ & 6 & -20.8850 & 17.5700 & 40.6931 \\
\hline $61-70$ & 2 & -24.7797 & 25.2094 & 35.7295 \\
\hline $71-80$ & 1 & -30.3523 & 22.4876 & 22.4954 \\
\hline $81-90$ & 1 & -43.0516 & 8.5529 & 10.5274 \\
\hline $91-100$ & 8 & -37.1808 & -2.0611 & 0.7655 \\
\hline
\end{tabular}

Change in Tolerant ASI

\begin{tabular}{|c|c|c|c|c|}
\hline $\begin{array}{l}\text { Beginning } \\
\text { ASI Class }\end{array}$ & Number of Lakes & $-50 \%$ & $0 \%$ & $+30 \%$ \\
\hline $0-10$ & 85 & -.071 & 0.1825 & 2.5868 \\
\hline $11-20$ &.-- & -. & -.. & $\ldots$ \\
\hline $21-30$ & 1 & -23.4182 & -2.5017 & 73.5805 \\
\hline $31-40$ & 1 & -26.4225 & 44.095 & 62.7599 \\
\hline $41-50$ &.- & -.- & $\ldots$ & -. \\
\hline $51-60$ & 1 & -57.7938 & 14.5657 & 42.1458 \\
\hline $61-70$ & -. & -.. & -. & -.- \\
\hline $71-80$ & -- & --- & -- & -- \\
\hline $81-90$ & 1 & -87.6647 & 7.4742 & 11.9343 \\
\hline $91-100$ & 2 & -73.7332 & 2.5868 & 3.2531 \\
\hline
\end{tabular}


TABLE A.5. (contd)

Change in Intermediate ASI

\begin{tabular}{|c|c|c|c|c|}
\hline $\begin{array}{l}\text { Beginning } \\
\text { ASI Class }\end{array}$ & Number of Lakes & $-50 \%$ & $0 \%$ & $+30 \%$ \\
\hline $0-10$ & 74 & -.229 & 0.22 & 4.0179 \\
\hline $11-20$ & 6 & -11.5060 & 35.7234 & 78.239 \\
\hline $21-30$ & 1 & 17.6694 & 32.5577 & 78.6724 \\
\hline $31-40$ & 1 & -29.63 & 62.0043 & 62.2502 \\
\hline $41-50$ & -- & -.. &.- & $\cdots$ \\
\hline $51-60$ & -.- & -- & --- & -- \\
\hline $61-70$ & 1 & -60.5753 & 22.5269 & 31.2073 \\
\hline $71-80$ & 1 & -78.0384 & -36.3764 & 20.4207 \\
\hline $81-90$ & -- & -- & -- & $\cdots$ \\
\hline $91-100$ & 7 & -58.8889 & 1.4122 & 1.4234 \\
\hline
\end{tabular}

\section{A.2 CPUE LINKAGE MODEL}

One way to estimate the relationship between CPUE and biological abundance is through observations of individual anglers at lakes where the biological quantities are known. Equation (A.4) shows the relationship that was applied to the intersection data set discussed in Section 2.2.

$$
\text { Individual Catch/Hour }=\alpha_{0}+\alpha_{i} z_{i}+\alpha_{j} z_{j}+\alpha_{k} \text { (ASI) }
$$

where $\quad z_{i}=$ individual characteristics (ABRS data)

$$
\begin{aligned}
& z_{j}=1 \mathrm{ake} / \mathrm{site} \text { characteristics (ELS data) } \\
& z_{k}=\text { ASI (DDRP models) }
\end{aligned}
$$

This equation predicts an individual's catch as a function of personal characteristics $\left(z_{i}\right)$, the site characteristics $\left(z_{j}\right)$, and the ASI. A separate equation was estimated for each of the trout species under consideration, because different species are found in different lakes, have different "catchability quotients," and are sought by anglers with different personal characteristics. The regression results for these estimations are reported in Table A.6. 
IABLE A.6. Catch per Unit Effort Regression Results by Species(a,b) Rainbow Trout Brown Trout Lake Trout Brook Trout

$\begin{array}{lllll}\text { Constant } & -.0505 & -1.902 & -1.542^{(c)} & -0.373 \\ & (0.215) & (-.2155) & (-12.76) & (-0.679)\end{array}$

Stress Indices

ASI Sensitive

$$
(-4.045)
$$

ASI Intermediate

$$
\begin{array}{ll}
-.0754^{(c)} & -1.989^{(c)} \\
(-19.20) & (-9.195)
\end{array}
$$

ASI Tolerant

$$
\begin{aligned}
& -4.987^{(c)} \\
& (-5.939)
\end{aligned}
$$

Fishing Mode

Fly Fishing
Rod
Spinning
Rod
Bait Casting
Rod

$-0.279^{(c)}$

$(-2.621)$

$$
\begin{gathered}
-.0820^{(c)} \\
(-3.632) \\
0.344^{(c)} \\
(13.02)
\end{gathered}
$$$$
-.05427^{(c)}
$$$$
(-7.581)
$$$$
-0.336^{(c)}
$$$$
(-5.362)
$$$$
-0.138
$$$$
-0.589^{(c)}
$$$$
(-1.042)
$$$$
(-8.369)
$$

Shore

$$
\begin{gathered}
0.364^{(c)} \\
(-3.674)
\end{gathered}
$$

\section{Watershed}

Deciduous

Trees

Pine Trees

$$
\begin{aligned}
& \left(10.5160^{(c)}\right. \\
& .0099^{(c)} \\
& (4.323)
\end{aligned}
$$

Agricul tural

$$
\begin{aligned}
& (12.007)^{(c)} \\
& .0067^{(c)} \\
& (-11.61)
\end{aligned}
$$$$
\begin{aligned}
& (10.76) \\
& \left(6.0066^{(c)}\right. \\
& (6.206)
\end{aligned}
$$

$$
\begin{aligned}
& . .0172^{(c)} \\
& (7.601) \\
& .0120^{(c)} \\
& (4.785) \\
& -.0250^{(c)} \\
& (-2.252)
\end{aligned}
$$

Water Quality

Visibility

$$
\begin{gathered}
-.0575^{(\mathrm{c})} \\
(-6.002) \\
-0.877^{(\mathrm{c})} \\
(-6.810) \\
0.608^{(\mathrm{c})} \\
(6.259)
\end{gathered}
$$

Lake

Weeds $(3,4,5)$

Weeds 3

$$
\begin{aligned}
& .0247^{(c)} \\
& (14.24) \\
& -8.089^{(c)} \\
& (-2.936)
\end{aligned}
$$$$
(4.146)^{(c)}
$$$$
0.718^{(\mathrm{c})}
$$$$
(10.10)
$$$$
-0.899 \text { (c) }
$$$$
(-8.481)
$$$$
0.364^{(c)}
$$$$
\text { (6.7403) }
$$

Launch

$$
{ }^{-1.052^{(c)}}
$$


TABLE A.6. (contd)

\begin{tabular}{|c|c|c|c|c|}
\hline \multicolumn{5}{|l|}{ Demographic } \\
\hline$\frac{\text { Demographic }}{\text { Age }}$ & $\begin{array}{l}-0.0022 \\
(-0.488)\end{array}$ & $\begin{array}{l}1.888^{(c)} \\
(13.21)^{-1}\end{array}$ & $\begin{array}{l}0.0217^{(c)} \\
(15.70)\end{array}$ & $(9.422)^{.0818^{(c)}}$ \\
\hline Retired & $\begin{array}{r}-.0305 \\
(-1.538)\end{array}$ & $\begin{array}{l}0.499^{(c)} \\
(5.724)\end{array}$ & & $\begin{array}{l}-1.703^{(c)} \\
(-4.738)\end{array}$ \\
\hline Income & & $(21.91)^{.00002^{(c)}}$ & & \\
\hline Education & & $\left(5.0243^{(c)}\right.$ & & $\begin{array}{l}-0.251^{(c)} \\
(-8.855)\end{array}$ \\
\hline Observations & 237 & 405 & 250 & 299 \\
\hline R-Square & 0.7396 & 0.8886 & 0.8187 & 0.8318 \\
\hline R-Bar Square & 0.7269 & 0.8855 & 0.8112 & 0.8253 \\
\hline
\end{tabular}

(a) T statistics are in parentheses.

(b) Dependent variable in rainbow and brook trout equations is the natural log of CPUE; the dependent variable in the lake trout and brown trout equations is CPUE.

(c) Significant at the 0.05 level.

The CPUE regressions are based on five basic kinds of information. These relate to the level of acidic stress, the fishing mode, watershed characteristics, water characteristics, and the demographic characteristics of anglers. The ASI indices were calculated from equations A.1, A.2, and A.3 using water chemistry information from the ELS. Fishing mode is a dummy variable, which was reported by the angler. The fishing gear questions (i.e., spinning rod, fly fishing rod, and bait casting rod) refer to the particular kind of fishing rod the angler was using. Shore refers to whether or not the angler was fishing from shore. The water shed characteristics are the same as those used in the forecasting equation. These characteristics are the percentage of shoreline with one variable type. Water quality variables include visibility, how deep the angler can see into the water, whether the water body is a pond, if the Likert weed scale is 3,4 , or 5 (Weeds $3,4,5$ ) and a Weeds 3 for a Likert scale of 3 . The launch variable is a dummy variable referring to 
the presence of a boat launch. The demographic variables relate to the age (in years), income (in \$), education (in years of education), and whether the person is retired.

From the 1265 angling trips available, only those where the angler expected to catch a fish species are included in that species CPUE regression. For example, a trip was included as an observation in the brown trout equation if an angler expected to catch brown trout on a trip (405 out of the 1265 trips). On some trips, of course, the angler expected to catch more than one species of trout. As a result, the total number of observations across the four CPUE regressions totals more than 1265.

The interpretation of the coefficients is straightforward. The coefficients relate the change in the rate of catch to a unit change in the variable. For example, shore anglers catch 0.364 more rainbow trout per hour than anglers in boats. Retired people catch 0.499 more brown trout per hour than do non-retired people. In this application, however, the only variable of interest in the analysis is the coefficient on the ASI indices. 


\section{APPENDIX B}

TRAVEL COST MODELS 


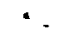


APPENDIX B

\section{IRAVEL COST MODELS}

This appendix details the specification of the two travel cost models, the hedonic travel cost model and the random utility model. Both models assume that the cost of travel to a site acts like the price, but each organizes angler decisions differently (see Englin and Kealy, 1990). The hedonic model directly estimates the value of site characteristics to an angler using standard regression techniques. Using maximum likelihood techniques, the random utility model estimates the probability that an angler will choose to visit a particular site. The value of individual site characteristics is estimated as probabilities rather than as proportions of total choices (as in the hedonic model).

\section{B.1 HEDONIC ANALYSIS}

The hedonic analysis of the recreational fishery data was completed in two stages. In the first stage, we examined the catch rates that anglers expected to achieve at a site. (a) The second stage focused on the mean of the actual catch at the site. Other features of the site, such as the percentage of particular forest types around the water body, remain the same across both analyses. Table B.1 shows each of the variables used in the hedonic analysis. Only visited sites are included in the hedonic cost estimation. By not visiting a site, anglers reveal that the costs of that site exceed its value. If inferior sites are included in the estimation, the cost to the user will be overestimated; the marginal costs will not reflect marginal values, and the hedonic coefficients will be biased.

The coefficients in these regressions represent the marginal distance an angler would have to travel for one more attribute. A positive value indicates that anglers from a specific origin would drive further to get more of

(a) Anglers were asked in the survey to estimate the expected catch rates for each of four species at each site visited. 
TABLE B.1. Variables Used in the Hedonic Analysis

Variable

Bass

Brook Trout

Brown Trout

Cold

Lake Trout

Largemouth

Bass

Shore Litter

Pan

People

Pick

Pine

Pond

Rainbow Trout

Smal1mouth

Bass

Trophy

Trout

Visibility
Description

The average catch per hour of all bass for all users of a site.

The average catch per hour of brook trout for all users of a site.

The average catch per hour of brown trout for all users of a site.

The average catch per hour of all types of cold water fish for all users of a site.

The average catch per hour of lake trout for all users of a site.

The average catch per hour of largemouth bass for all users of a site.

The absence of visible Shore Litter near the site $(0,1)$.

The average catch per hour of all pan fish for all users of a site.

The number of users at a site as reported by the anglers; a measure of congestion.

The average catch per hour of pickerel for all users of a site.

The percentage of shoreline covered by evergreen trees.

A dummy variable which is 1 if a pond and 0 otherwise.

The average catch per hour of rainbow trout for all users of a site.

The average catch per hour of smallmouth bass for all users of a site.

Whether a site was a trophy site $(0,1)$.

The average catch per hour of all trout for all users of a site.

The depth at which the angler could see the bottom as reported by the angler. 


\section{TABLE B.1. (contd)}

Walk

Warm

Weeds
The distance in miles one has to walk to get access to the site.

The average catch per hour of all warm water fish across all users of a site.

A dummy variable which was 0 if the weeds question on the questionnaire was answered no visible weeds.

the characteristic; a negative value indicates that anglers drive farther to get less of the characteristic. These hedonic price coefficients are in miles per trip. To convert distance costs into dollar costs, the coefficients are multiplied by the per-mile travel cost.

There are at least three reasons for these estimations to produce insignificant coefficients. First, there may not be enough variation in the characteristic across the sample of observed sites. Second, the existing variation of attributes must be independent. However, ecologically related characteristics may be spatially correlated with each other. Omitted variables may have an unknown influence on the coefficients and separate valuation is not always possible. Third, if individuals do not value a characteristic, their travel behavior may not be systematically correlated with it.

\section{B.1.1 Expected Catch Results}

Because little research has been done to carefully define what site characteristics are important to anglers, we explored several different regression specifications for the first-stage hedonic regressions. In past hedonic studies, the most important characteristic varied. For example, Brown and Mendelsohn (1984) found that catch rate was most important to steelhead anglers in Washington State, but Mendel sohn et al. (1984) found that fish size mattered most to trout anglers in Montana. Therefore, we began our analysis with a relatively simple specification including warm and cold water expected catch rates, the mean of trophy fish caught, the presence of a boat 1 aunch, and a dummy for pond (versus lake):

$$
\text { Distance }=a_{0}+a_{1} \text { Cold }+a_{3} \text { Warm }+a_{4} \text { Trophy }+a_{5} \text { Launch }+a_{6} \text { Pond }
$$


Because the configuration of destinations is potentially different for each origin, the regression must be run separately for each origin. There was a total of 43 origins. However, trips from three origins went to only a handful of sites, so that coefficients for these origins could not be estimated. As a result, this regression was estimated for each of the 40 origins. Many of the coefficients in these regressions were significant but the significant coefficients were both positive and negative. For example, for 9 origins, people drove further for higher warm water fish catch rates, but for 11 origins they drove further for lower warm water catch rates. Similar negative and positive coefficients occurred for trophy fish, with 12 positive coefficients and 9 negative coefficients. In contrast, 16 origins reported a positive coefficient for cold water fishing and only 8 a negative coefficient. Similarly, 14 coefficients were negative for both the launch variable and pond variable, while 8 and 9 were positive. The results are thus mixed but indicate a preference for higher cold water catch rates, 1akes, and sites without 1 aunch facilities.

The second regression explored preferences for specific species of fish. This analysis identifies pickerel, bass, trout, and pan fish:

$$
\text { Distance }=a_{0}+a_{1} \text { Pick }+a_{2} \text { Bass }+a_{3} \text { Trout }+a_{4} \text { Pan }
$$

Again, the regression was attempted for each of 40 origins, but three origins did not support an analysis. The results of this analysis were mixed for every species except pickerel. Of 19 significant coefficients for pickerel, 16 were positive, indicating a clear preference for higher pickerel catch rates. Of 21 significant coefficients for trout, 13 were positive, indicating a slight preference for higher trout catch rates. Bass and pan fish also had 20 significant coefficients, but the positive and negative signs for both fish were evenly split, indicating no clear preferences.

The results of these first two regressions indicated that some noncatch site characteristics were important in clarifying expected catch rates. We, therefore, explored some additional specifications that included the expected catch rates species and features of the site. For example, Equation (B.3) is a combination of Equations (B.1) and (B.2): 


$$
\begin{aligned}
\text { Distance }= & a_{0}+a_{1} \text { Pick }+a_{2} \text { Bass }+a_{3} \text { Trout }+a_{4} \text { Pan }+a_{5} \text { Trophy } \\
& +a_{6} \text { Launch }+a_{7} \text { Pond }
\end{aligned}
$$

Both the pickerel and trout results remain strong under this specification, with 12 positive significant coefficients each and only 6 and 7 negative coefficients, respectively. Bass catch rates remain split, with 9 positive and 9 negative coefficients. However, pan fish catch rates turn negative, with 12 negative and only 7 positive coefficients. Thus, controlling for site features, higher pan fish catch rates are not necessarily an improvement. The results for trophy fish improve slightly compared to Equation (B.1), with 12 positive and 9 negative significant coefficients. Boat launch sites and ponds remain undesirable.

The next regression attempted to define the desired species mix more precisely. Trout catch rates were split between all cold water and rainbow trout. Instead of all bass catch rates, 1 argemouth bass alone were specified. Finally, warm water catch rates were included for all other fish, yielding Equation (B.4).

$$
\begin{aligned}
\text { Distance }= & a_{0}+a_{1} \text { Pick }+a_{2} \text { LBass }+a_{3} \text { RainTr }+a_{4} \text { Warm }+a_{5} \text { Cold } \\
& +a_{6} \text { Launch }+a_{7} \text { Pond }+a_{8} \text { Trophy }
\end{aligned}
$$

The results improved the performance of expected cold water catch rates, with 13 positive significant coefficients and only 5 negative coefficients. Pickerel also boasted 16 positive against only 4 negative coefficients. Rainbow trout, warm water catch rates, and largemouth bass, however, all had about as many positive and negative coefficients. Trophy fish, launch sites, and ponds were also evenly split.

Additional site features were explored using the same configuration of fish species. In Equation (B.5), the presence of bacteria, the fraction of pine trees on the shoreline, and the visibility of the water were all included as site features: 


$$
\begin{aligned}
\text { Distance }= & a_{0}+a_{1} \text { Pick }+a_{2} \text { LBass }+a_{3} \text { RainTr }+a_{4} \text { Warm }+a_{5} \text { Cold } \\
& +a_{6} \text { Bacteria }+a_{7} \text { Pine }+a_{8} \text { Visibility }
\end{aligned}
$$

The coefficients for fish catch remain similar to the results of Equation (B.4). Both bacteria and visibility split positive and negative coefficients. Only the percentage of pine cover on the shore has a clear positive influence, with 9 positive and 5 negative coefficients.

Equation (B.6) retained the same species mix as Equation (B.5), but included number of other people, no garbage, and the presence of weeds as independent variables.

$$
\begin{aligned}
\text { Distance }= & a_{0}+a_{1} \text { Pick }+a_{2} \text { LBass }+a_{3} \text { RainTr }+a_{4} \text { Warm }+a_{5} \text { Cold } \\
& +a_{6} \text { People }+a_{7} \text { No Garbage }+a_{8} \text { Weeds }
\end{aligned}
$$

The fish species coefficients remained about the same. However, all three site features tended to be valued positively. There were 7, 11, and 10 positive significant coefficients for people, no garbage, and weeds, but only 3 , 4 , and 6 negative coefficients for these characteristics. The strong results for the no-garbage variable encouraged its inclusion in later regressions.

In Equation (B.7), the strongest variables from the previous six regressions were introduced together. Fish species were cold water, lake trout, warm water, and pickerel, with trophy fish for size. Pond, pine, and no garbage were included as other site features:

$$
\begin{aligned}
\text { Distance }= & a_{0}+a_{1} \text { Pick }+a_{2} \text { LakeTr }+a_{3} \text { Warm }+a_{4} \text { Cold }+a_{5} \text { Trophy } \\
& +a_{6} \text { Pine }+a_{7} \text { No Garbage }+a_{8} \text { Pond }
\end{aligned}
$$

The results of Equation (B.7) were encouraging for the 31 origins with enough different destinations to estimate the above equation. Higher catch rates of cold water, lake trout, and pickerel were clearly desired, with 15, 13, and 14 positive significant coefficients and only 7,6 , and 7 negative coefficients. Warm water catch rates were again split evenly. Trophy fish had 12 positive coefficients and 8 negative coefficients. Ponds and pine were split evenly. No garbage had 13 positive significant coefficients and 5 negative coefficients. 


\section{B.1.2 Mean Actual Catch Rates}

Based upon information gained from examining expected catch rates, fewer specifications were tried with actual catch rates. Four different exploratory specifications were attempted using actual mean catch rates as independent variables in a hedonic price regression. The specifications followed those attempted for expected catch rates except that more detail was added on fish species and an additional variable, miles walked, was included in some regressions. The simplest regression estimated using actual catch rates was Equation (B.8):

$$
\text { Distance }=a_{0}+a_{1} \text { Cold }+a_{2} \text { Warm }+a_{3} \text { Trophy }+a_{4} \text { Garbage }+a_{5} \text { Pond (B.8) }
$$

In this regression, 13 of the cold water fish coefficients were positive and 7 were negative. In contrast, 10 warm water fish coefficients were positive and 15 were negative. Trophy had 13 positive coefficients and only 8 negative coefficients. Pond had 11 negative and 6 positive coefficients. No garbage was split evenly, with 22 significant coefficients.

The next regression used the same variables for site features but added more detail on fish species by including variables for pickerel, pan, bass, and trout. Pickerel and trout had 13 positive significant coefficients but 9 and 10 negative coefficients respectively. Pan was evenly split between positive and negative coefficients. Bass had 8 positive and 15 negative coefficients. Trophy performed much more strongly, with 16 positive significant coefficients and only 4 negative coefficients. Pond was mostly negative (11- versus $7+$ ), and garbage was evenly split.

The next regression changed the species mix and added a new variable, miles walked. The new fish categories were cold water, lake trout, warm water and pickerel, as indicated in Equation (B.9):

$$
\begin{aligned}
\text { Distance }= & a_{0}+a_{1} \text { Pick }+a_{3} \text { LakeTr }+a_{4} \text { Warm }+a_{5} \text { Cold }+a_{6} \text { Trophy } \\
& +a_{7} \text { Walk }+a_{8} \text { No Garbage }+a_{9} \text { Pond }
\end{aligned}
$$

Cold water and lake trout had more positive coefficients than negative (6+vs. 3- and 9+ vs. 3-). Warm water catch rates had a negative coefficient while 
pickerel split evenly. Trophy fishing had 9 positive and only 2 negative coefficients. Garbage was split evenly. Walking had 11 significant negative coefficients.

To get more detail on trout and bass fishing, the following specification was run:

$$
\begin{aligned}
\text { Distance }= & a_{0}+a_{1} \text { Rain }+a_{3} \text { LakeTr }+a_{4} \text { Brown }+a_{5} \text { Brook }+a_{6} \text { LBass } \\
& +a_{7} \text { SmBass }+a_{8} \text { Trophy }+a_{9} \text { No Garbage }+a_{10} \text { Pond }
\end{aligned}
$$

The results of this exploration indicated a positive preference for rainbow trout $(10+$ vs. 5-), brook trout $(12+$ vs. 4-), and lake trout $(10+$ vs. 7-), with mixed results for 1 argemouth bass (5+ vs. 6-), and distaste for brown trout (3+ vs. 7-) and smallmouth bass (6+ vs. 10-). Trophy fish were still desired, with 10 positive versus 6 negative coefficients. Pond and no garbage were evenly split.

A specification was attempted focusing upon trout species only. Variables were also added to Equation (B.11) for miles walked and presence of weeds.

$$
\begin{aligned}
\text { Distance }= & a_{0}+a_{1} \text { Rain }+a_{2} \text { LakeTr }+a_{3} \text { Brown }+a_{4} \text { Brook }+a_{5} \text { Trophy } \\
& +a_{6} \text { Weeds }+a_{7} \text { Walk }+a_{8} \text { No Garbage }+a_{9} \text { Pond }
\end{aligned}
$$

The results were mixed, with almost as many positive and negative coefficients except for brook trout, which had 3 positive and 7 negative coefficients. Weeds and ponds were evenly split in signs, trophy (8+ versus 7-) and no garbage (7+ versus $3-)$ were mostly positive, and miles walked (12-) entirely negative.

The final specification to calculate total cost per trip values is given in Equation (B.12):

$$
\begin{aligned}
\text { Distance }= & a_{0}+a_{1} \text { Rain }+a_{3} \text { Brown }+a_{4} \text { Brook }+a_{5} \text { LakeTr }+a_{6} \text { Weeds } \\
& +a_{7} \text { Trophy }+a_{8} \text { Pond }+a_{9} \text { No Garbage }
\end{aligned}
$$




\section{B.1.3 Results}

The results of the hedonic price regression are given in Table B. 2 by county of origin for 29 counties. (Table B.3 lists the names and populations of the counties in the survey.) The numbers in each cell of Table B.2 represent the miles traveled by anglers to get one more unit of the characteristic (e.g., one more trout). These are the current catch per unit effort (CPUE) values in terms of miles per trip. To calculate the marginal social value associated with trout catch rates, the combined marginal costs for the four trout species were summed across counties then divided by the total number of trips.

To calculate the change in CPUE associated with a change in deposition, the current trout hedonic prices for each county are multiplied by the projected change in CPUE (calculated from the physical data) for each lake visited by anglers from that county. These values are summed over all counties and divided by the total number of trips as indicated by Equation (B.13) in order to calculate an overall \$/trip value associated with the scenario.

$$
\$ / \text { trip }=\left[\left\{\sum_{i j}\left(t_{i} * \Delta \mathrm{CPUE}_{i j}\right)\right\} / \text { No. trips }\right] * \text { per-mile travel cost }
$$

where $i=$ origins

$j=$ number of trips

$t=$ willingness-to-travel for a marginal increase in an attribute.

This equation was estimated for the two NAPAP reduction scenarios (S1 and S4) and the three sensitivity analyses. In addition, a further analysis was done for Adirondack lakes only, using historical information. This current damages analysis uses the same relationships but limits the geographic coverage to the Adirondack region. The result is an estimate of the additional social welfare that would have been achieved without current levels of acidification. 
TABLE B.2. Hedonic Coefficients for 29 Counties( $^{(a, b)}$

\begin{tabular}{|c|c|c|c|c|c|}
\hline Variable & $\begin{array}{l}\text { Oxford } \\
\text { County (ME) }\end{array}$ & $\begin{array}{l}\text { Piscataquis } \\
\text { County (ME) }\end{array}$ & $\begin{array}{c}\text { Sagadahoc } \\
\text { County (ME) }\end{array}$ & $\begin{array}{c}\text { Somerset } \\
\text { County (ME) }\end{array}$ & $\begin{array}{l}\text { Washington } \\
\text { County (ME) }\end{array}$ \\
\hline Constant & $\begin{array}{l}-11.66^{(c)} \\
(-1.83)\end{array}$ & $\begin{array}{l}-3.71 \\
(-0.34)\end{array}$ & $\begin{array}{l}-78.59^{(d)} \\
(-3.33)\end{array}$ & $\begin{array}{l}1.48 \\
(0.15)\end{array}$ & $\begin{array}{l}14.89^{(d)} \\
(2.04)\end{array}$ \\
\hline Rainbow Trout & $\begin{array}{l}-2.56^{(c)} \\
(-1.76)\end{array}$ & $\begin{array}{l}5.32^{(d)} \\
(2.60)\end{array}$ & $\begin{array}{c}126.28 \\
(1.56)\end{array}$ & $\begin{array}{l}-13.43 \\
(-0.82)\end{array}$ & $\begin{array}{l}-7.17 \\
(-0.46)\end{array}$ \\
\hline Brown Trout & $\begin{array}{l}-22.92^{(d)} \\
(-7.04)\end{array}$ & $\begin{array}{l}-23.32 \\
(-0.47)\end{array}$ & $\begin{array}{c}-495.50^{(d)} \\
(-1.91)\end{array}$ & $\begin{array}{l}-9.22^{(d)} \\
(-2.07)\end{array}$ & $\begin{array}{l}-26.75^{(d)} \\
(-2.26)\end{array}$ \\
\hline Brook Trout & $\begin{array}{c}0.33 \\
(0.58)\end{array}$ & $\begin{array}{l}18.68^{(d)} \\
(4.07)\end{array}$ & $\begin{array}{l}434.53^{(d)} \\
(14.43)\end{array}$ & $\begin{array}{c}0.43 \\
(0.26)\end{array}$ & $\begin{array}{l}13.51^{(d)} \\
(13.42)\end{array}$ \\
\hline Lake Trout & $\begin{array}{l}11.81^{(d)} \\
(2.19)\end{array}$ & $\begin{array}{l}-10.72 \\
(-1.27)\end{array}$ & $\begin{array}{c}-333.06^{(d)} \\
(-3.15)\end{array}$ & $\begin{array}{c}8.23 \\
(0.52)\end{array}$ & $\begin{array}{l}48.47 \\
(0.98)\end{array}$ \\
\hline Weeds & $\begin{array}{l}-4.87^{(d)} \\
(-5.61)\end{array}$ & $\begin{array}{l}1.16 \\
(0.35)\end{array}$ & $\begin{array}{l}27.12^{\text {(d) }} \\
(3.21)\end{array}$ & $\begin{array}{l}3.35^{(c)} \\
(1.78)\end{array}$ & $\begin{array}{l}-4.92^{(d)} \\
(-2.72)\end{array}$ \\
\hline Trophy Lake & $\begin{array}{l}25.33^{(d)} \\
(12.13)\end{array}$ & $\begin{array}{c}-0.76 \\
(-0.11)\end{array}$ & $\begin{array}{l}-14.28 \\
(-1.48)\end{array}$ & $\begin{array}{l}12.16^{(d)} \\
(3.43)\end{array}$ & $\begin{array}{l}20.88^{(d)} \\
(3.89)\end{array}$ \\
\hline Pond & $\begin{array}{l}0.14^{(c)} \\
(640.54)\end{array}$ & $\begin{array}{l}-2.20 \\
(-0.50)\end{array}$ & $\begin{array}{c}8.18 \\
(1.48)\end{array}$ & $\begin{array}{l}14.68^{(d)} \\
(5.16)\end{array}$ & $\begin{array}{l}-14.01^{(d)} \\
(-2.26)\end{array}$ \\
\hline Shore Litter & $\begin{array}{l}7.14^{(d)} \\
(6.56)\end{array}$ & $\begin{array}{c}2.73 \\
(1.58)\end{array}$ & $\begin{array}{l}15.97^{(d)} \\
(4.60)\end{array}$ & $\begin{array}{c}0.43 \\
(0.19)\end{array}$ & $\begin{array}{c}2.23 \\
(1.19)\end{array}$ \\
\hline Observations & 416 & 196 & 89 & 500 & 159 \\
\hline R-Squared & 0.68 & 0.15 & 0.82 & 0.10 & 0.68 \\
\hline Corrected R-Squared & 0.67 & 0.11 & 0.81 & 9.28 & 0.66 \\
\hline
\end{tabular}

\footnotetext{
(a) Values represent marginal distance in miles associated with each variable.

(b) T-statistics are in parentheses.

(c) Significant at the $90 \%$ level.

(d) Significant at the $95 \%$ level.
} 


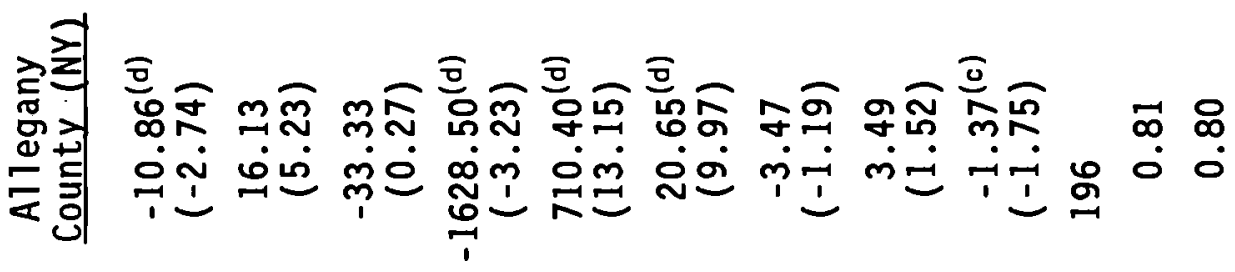

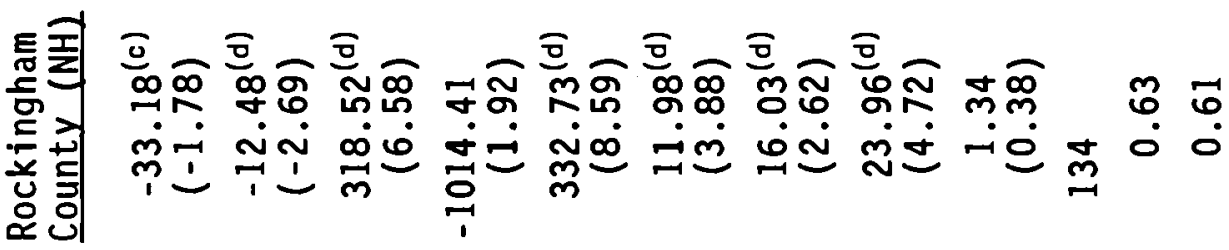

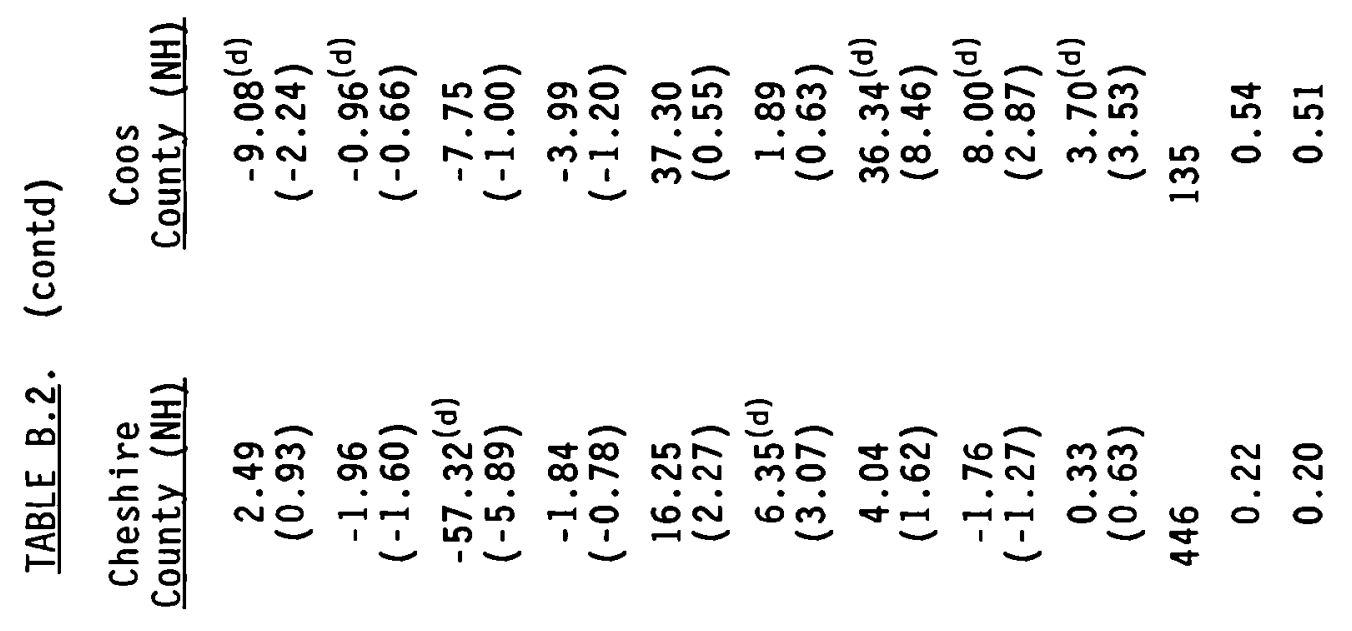

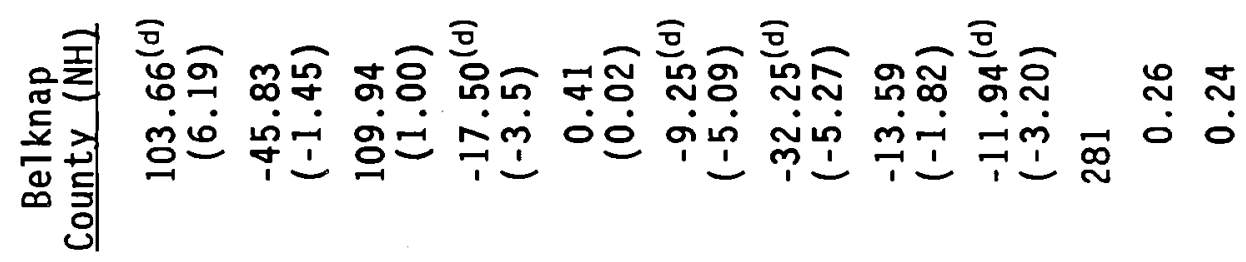

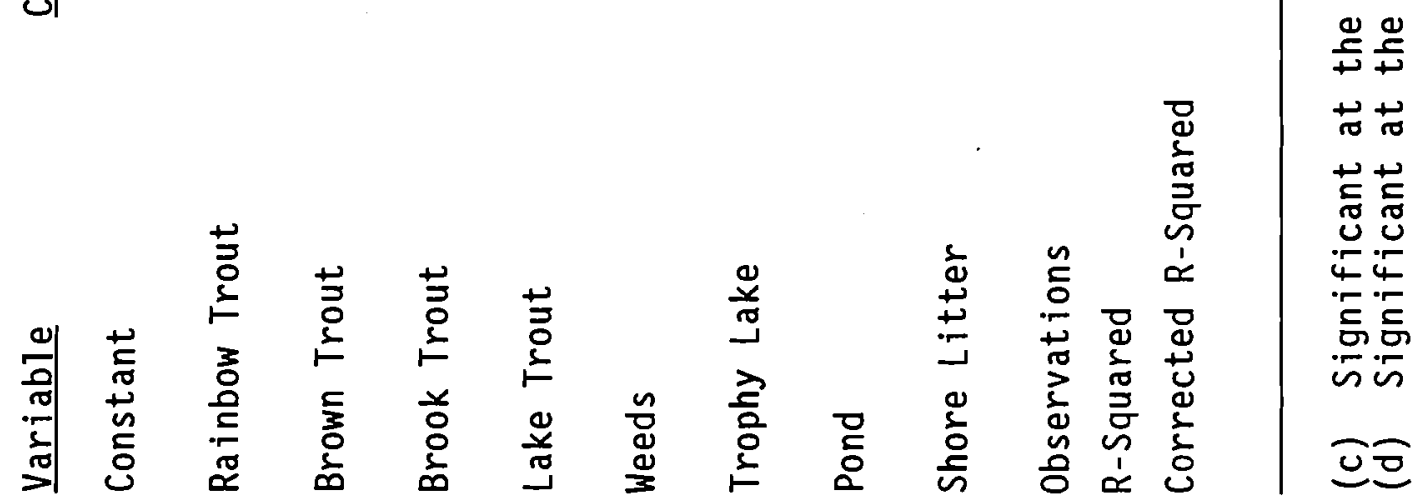




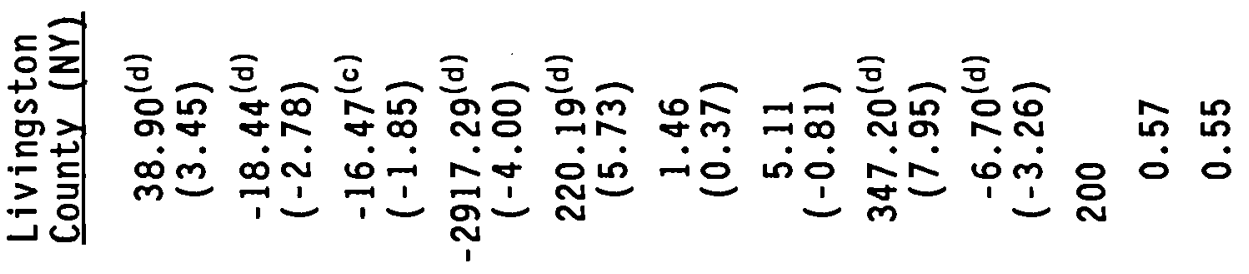

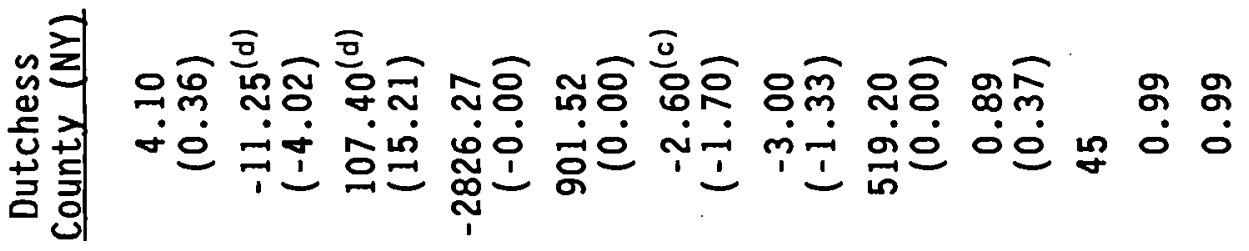

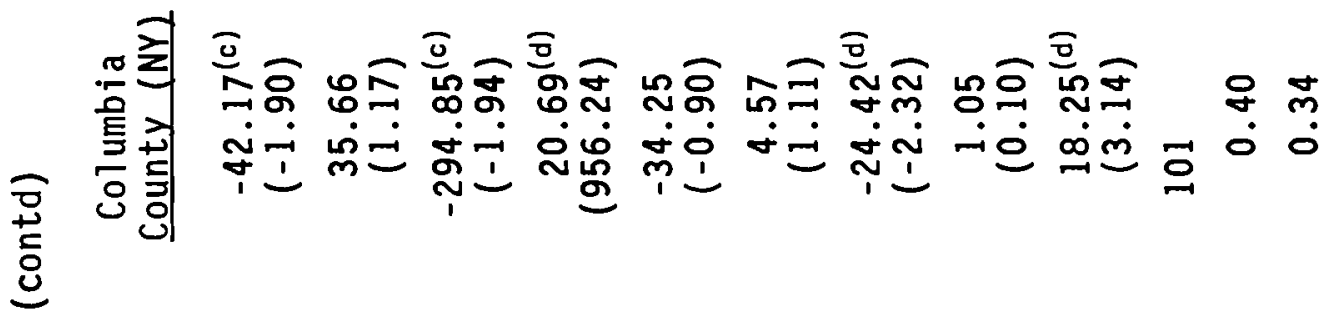

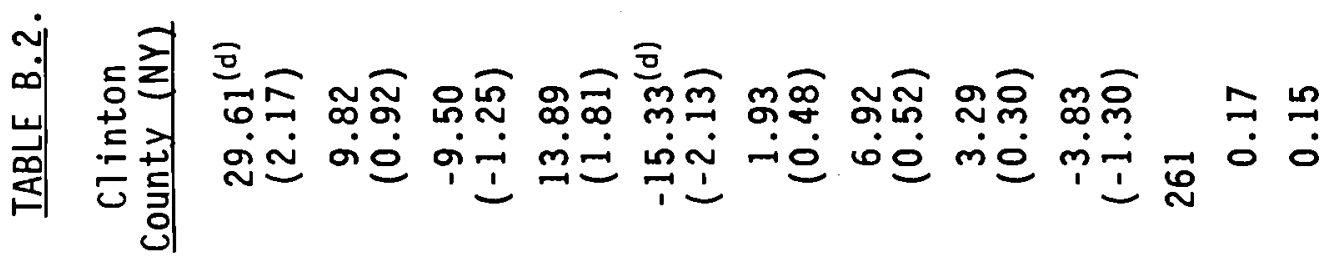

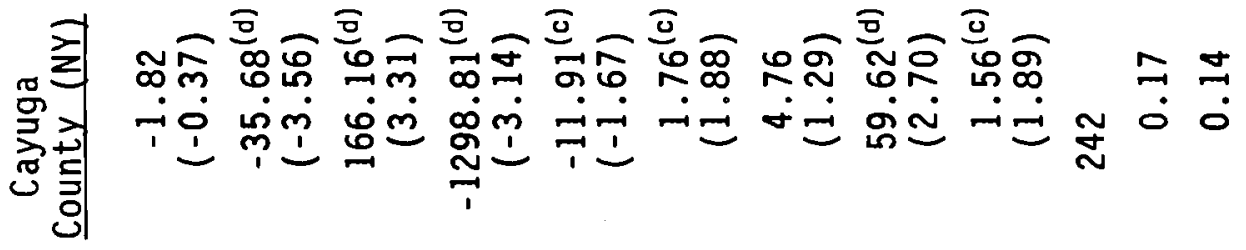

㐫

รัํํㅇํ

吉哭

岩苗

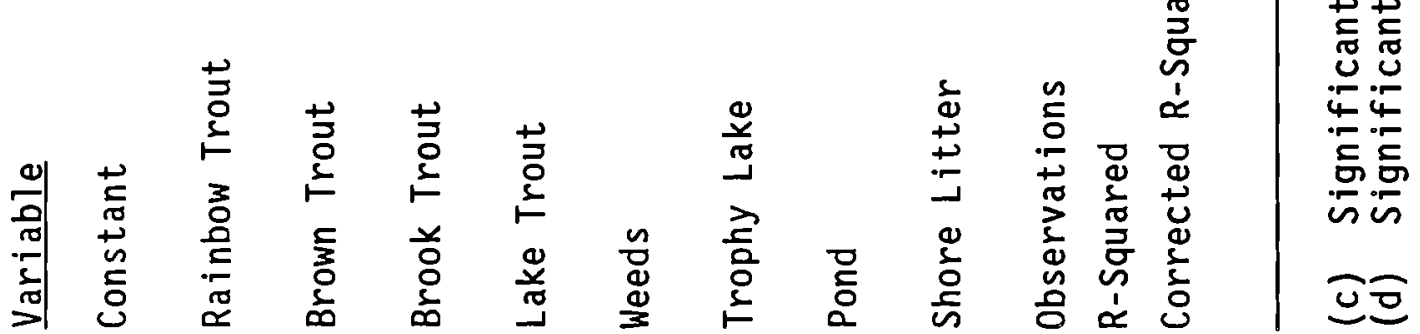




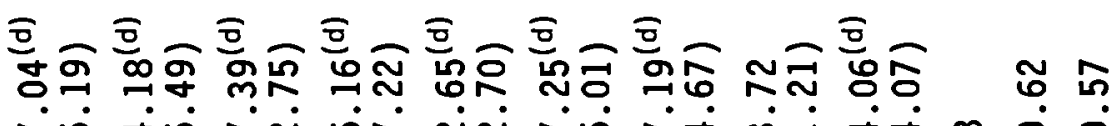

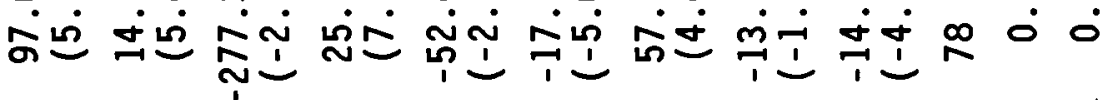

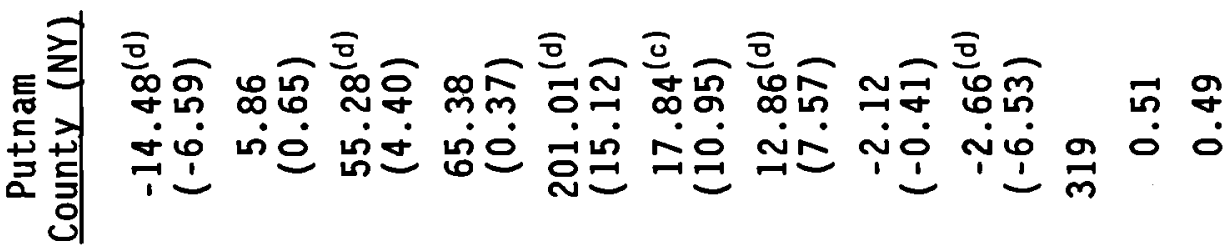

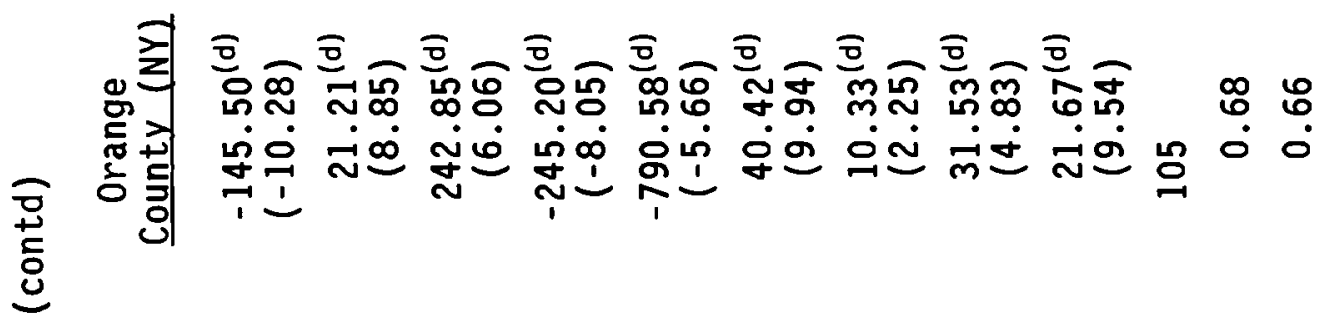

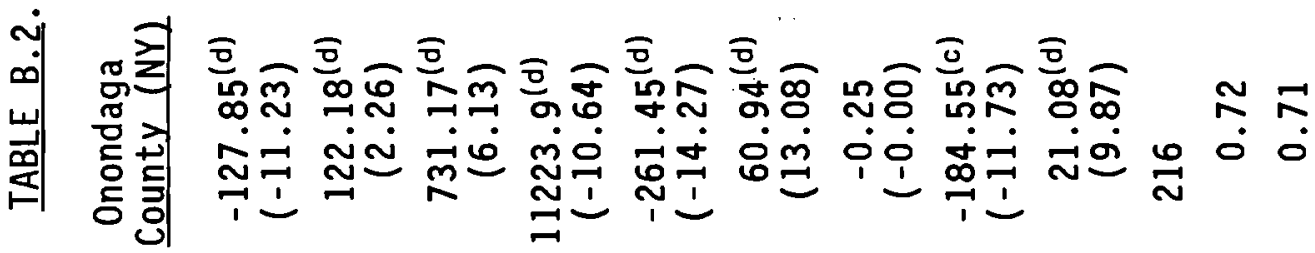

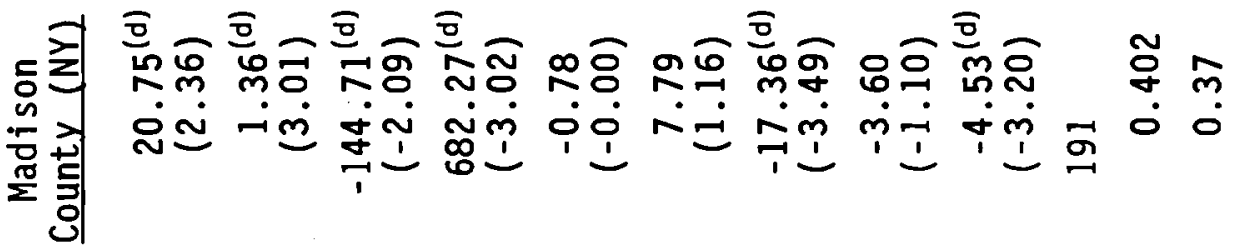

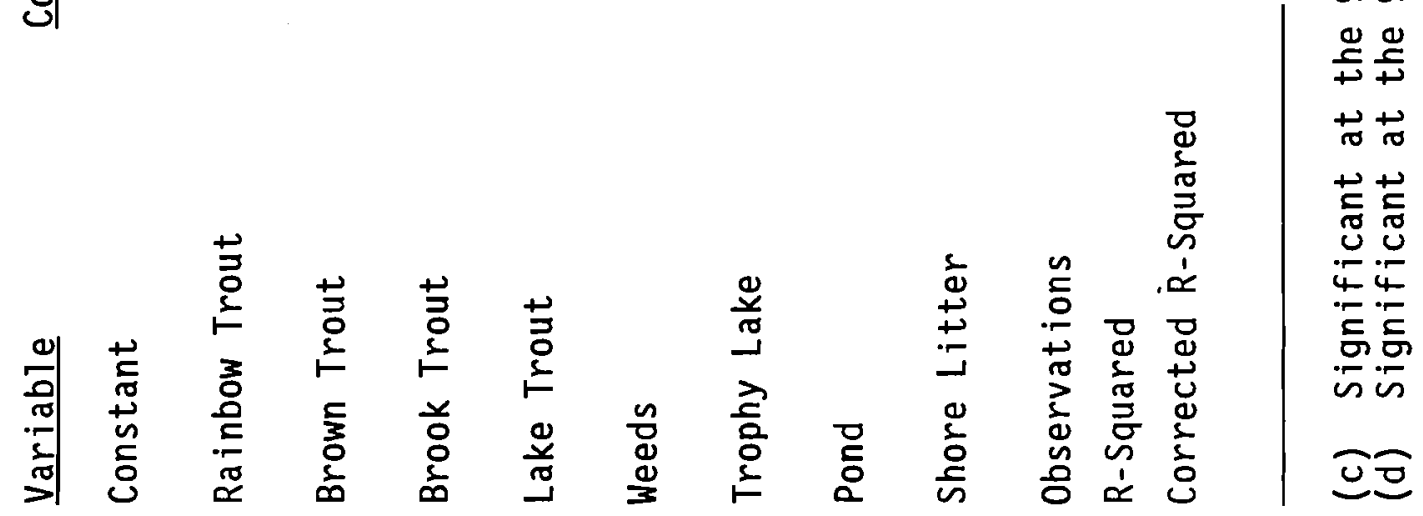


鼻

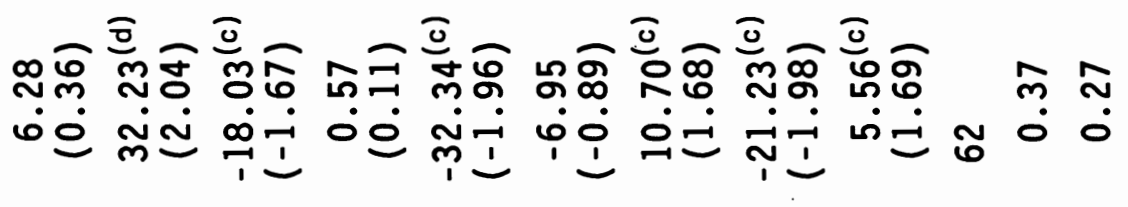

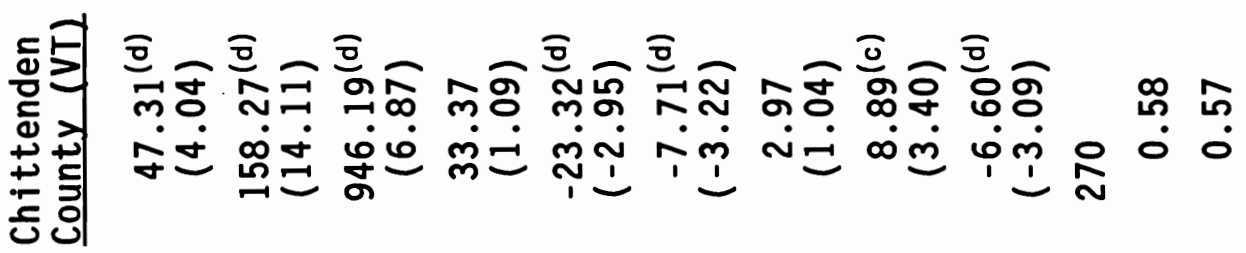

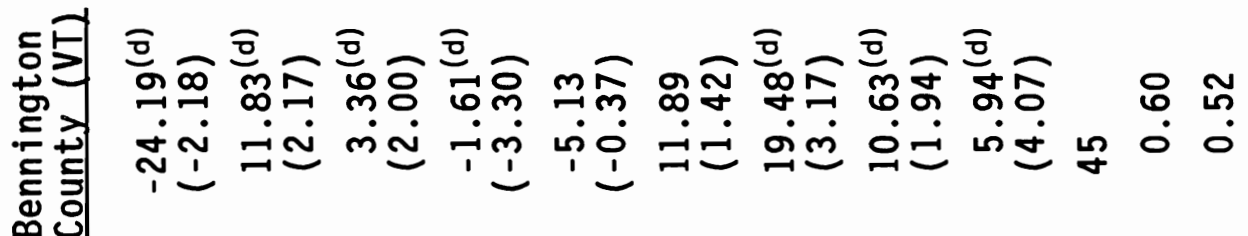

ఫ્

느

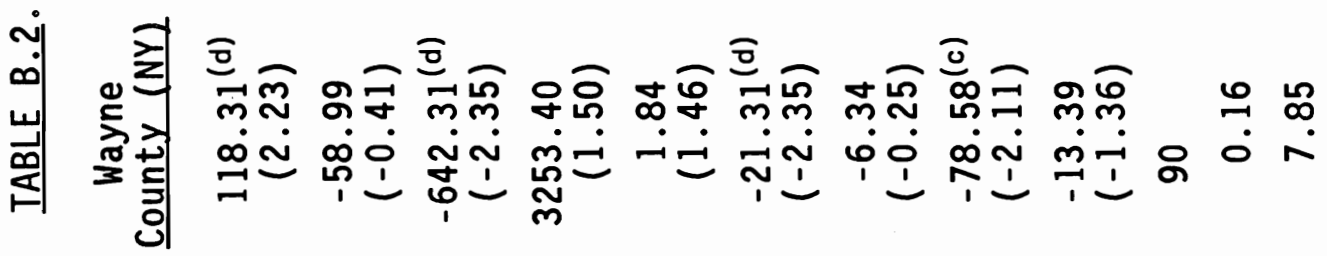

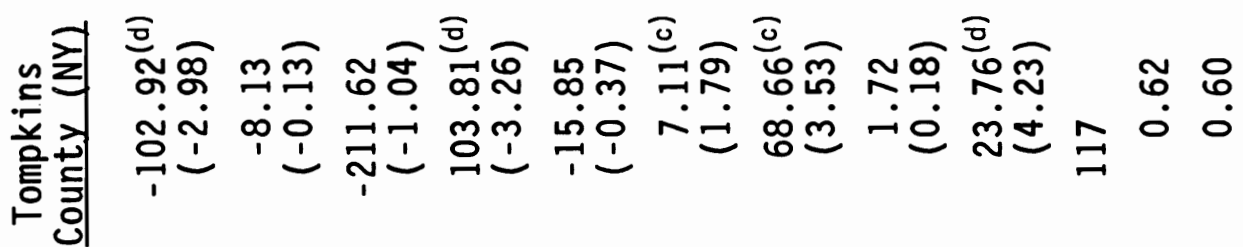

¿্ঠ

ㅇํㅇํํ

옴

苗

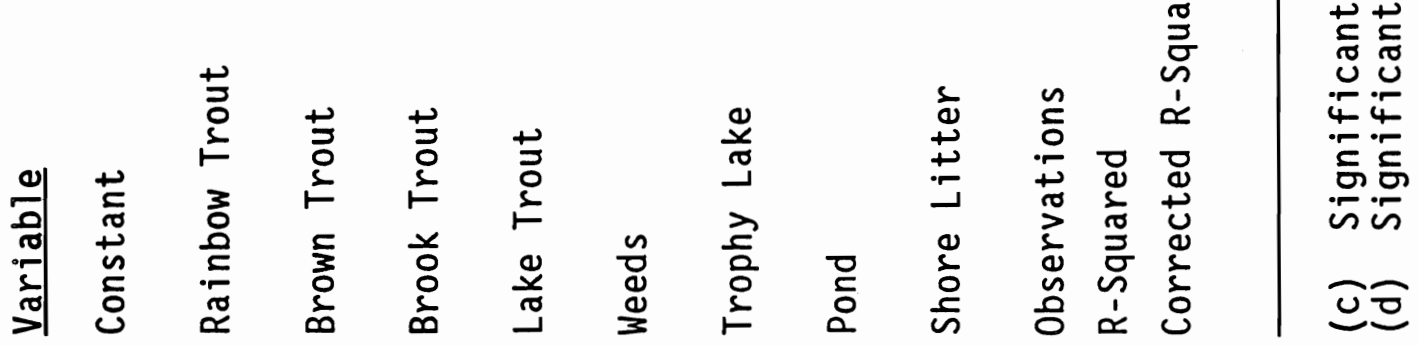




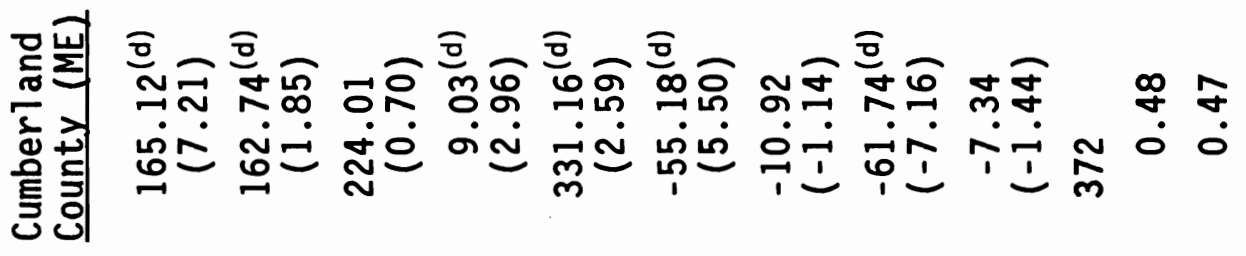

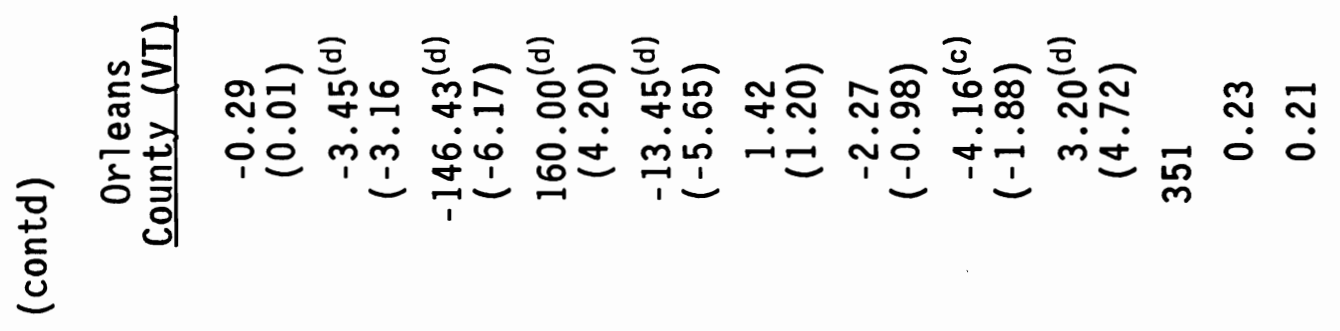

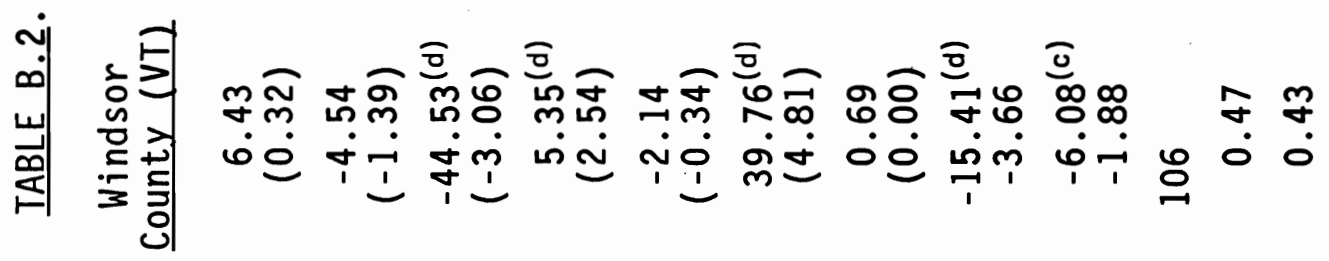

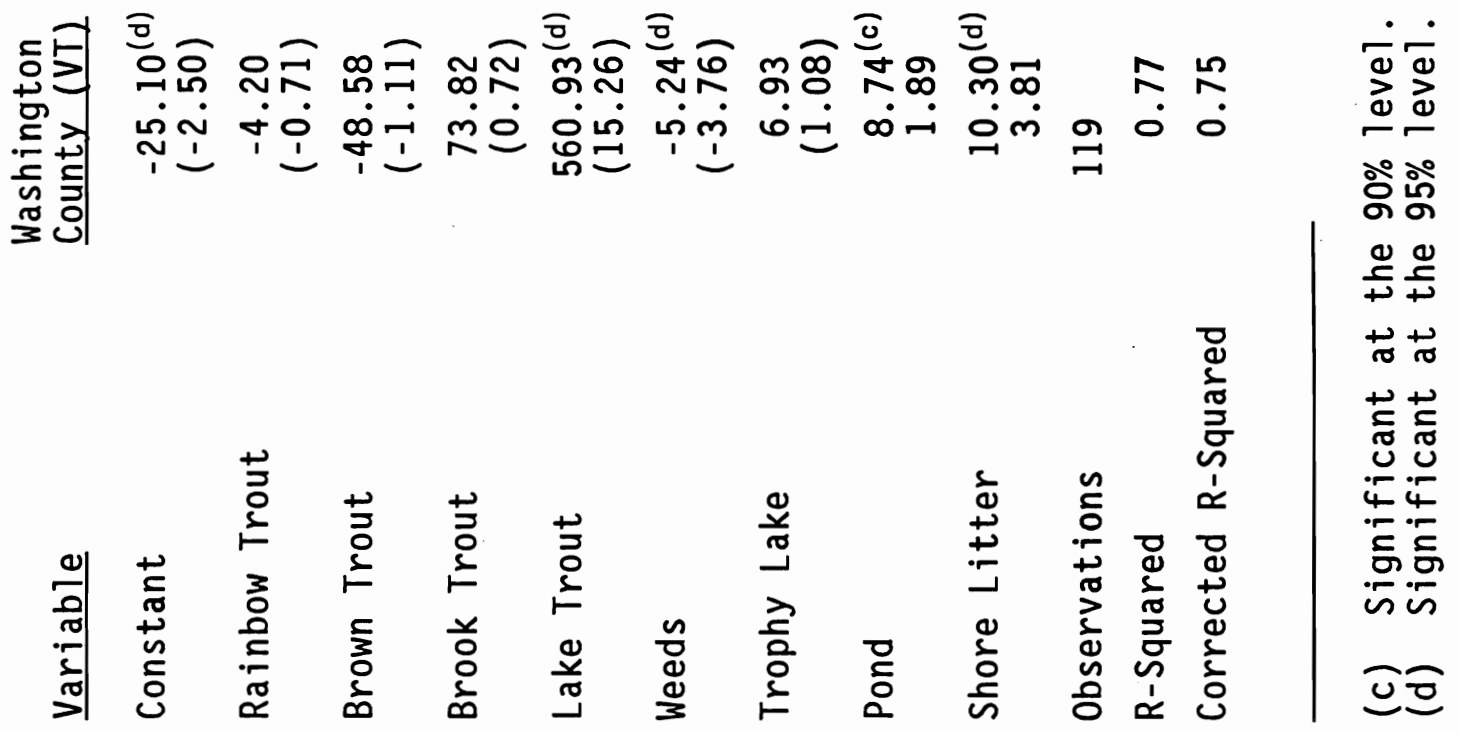


TABLE B.3. Names and Populations of the Counties in the Survey

\begin{aligned} \multicolumn{1}{c}{ State } \\ \hline 1 Maine \\ 2 Maine \\ 3 Maine \\ 4 Maine \\ 5 Maine \\ 6 Maine \\ 7 New Hampshire \\ 8 New Hampshire \\ 9 New Hampshire \\ 10 New Hampshire \end{aligned}

11 New York

12 New York

13 New York

14 New York

15 New York

16 New York

17 New York

18 New York

19 New York

20 New York

21 New York

22 New York

23 New York

24 New York

25 New York

26 New York

27 New York

28 New York

29 New York

30 New York

31 New York

32 New York

33 New York

34 New York

35 Vermont

36 Vermont

37 Vermont

38 Vermont

39 Vermont

40 Vermont

\section{County Population}

Cumberland $\quad 215,789$

Oxford 49,043

Piscataquis $\quad 17,634$

Sagadahoc 28,795

Somerset $\quad 45,049$

Washington $\quad 34,963$

Belknap

42,884

Cheshire 62,116

Coos

35,147

Rockingham $\quad 190,345$

Allegany $\quad 51,742$

Broome 213,648

Cayuga $\quad 79,894$

Chautauqua $\quad 146,925$

Chemung $\quad 97,656$

Clinton $\quad 80,750$

Columbia $\quad 59,487$

Dutchess 245,055

Erie $\quad 1,015,472$

Herkimer $\quad 66,714$

Jefferson $\quad 88,151$

Livingston $\quad 57,006$

Madison $\quad 65,150$

Nassau $\quad 1,321,582$

Niagara $\quad 227,354$

Onondaga $\quad 463,920$

Orange 259,603

Oswego 113,901

Putnam 77,193

St. Lawrence 114,347

Suffolk $\quad 1,284,231$

Tompkins $\quad 87,085$

Wayne

Westchester 866,599

Bennington $\quad 33,345$

Chittenden 115,534

Orange 22,739

Orleans 23,440

Washington $\quad 52,393$

Windsor $\quad 51,030$ 


\section{B.2 RUM ANALYSIS}

The random utility model was estimated using the subset of individuals from the Recreational Fishing Survey who made at least one day-trip to a lake in Maine, New Hampshire, Vermont, or New York. (Individuals from Long Island were excluded as were trips to any of the Great Lakes.) The final data set included information on 530 individuals and 6,291 trips. Because each person had possibly hundreds, if not thousands, of lakes for a day-trip, we used a random draw of lakes to represent each angler's opportunity set. The procedure used was as follows:

First, the set of all lakes actually visited by at least one person in the sample was formed. Second, each lake was assigned a nearby town to define its location. Third, the distance from each angler's home town to all lakes within a day's drive ( 3 hours) was completed using HYWAYS/BYWAYS software. Fourth, for each individual, 11 lakes were randomly drawn from the set of lakes developed in the previous step. These 11 lakes plus the lake actually visited represents the angler's opportunity set. Fifth, the model was estimated (each angler having 12 lakes in a set) by standard multinominal logit procedure using LIMDEP software.

Using only the set of actually visited lakes and using random draws implicitly assumes that individuals' preferences exhibit independence of irrelevant alternatives. In the model specification used in this analysis, step four was modified. If a person was targeting trout on a given trip, only those lakes with reported expected catches of trout were included in the draw. The same was true for targeting the other species. Again, this is possible without biasing parameter estimates if we accept independence of irrelevant alternatives.

\section{B.2.1 Model Specification}

The final specification was a non-nested model of day trips to lakes that included explanatory variables for price (travel and time cost), catch rate of targeted species, and characteristics believed to matter to individuals when making a fishing trip: scenic view, presence of a boat ramp, lake 
size, and whether the lake is located in the same state in which the individual lives. The model assumes that utility for a trip to a given lake is a linear function of these variables.

For individuals with flexible work schedules, price is travel cost only; opportunity cost of time is entered as the separate variable time cost. Four catch rate variables enter the function: catch rate per hour of trout, bass, pike, and pan. Trout is the average catch rate of all trout species at a lake; bass is the average catch rate of smallmouth, largemouth, and other bass; pike is the average catch rate of northern and walleye pike; and pan is the average catch rate of all other species.

The catch rates at each lake are based on expected catches reported by people interviewed in the Recreational Fishing Survey (anglers were asked which, if any, species they targeted on their trips). Averages were calculated over each species group for each lake. (a) For each individual, only the catch rate for the aggregate group in which the targeted species is a member enters the function. (b) For example, if a person targeted smallmouth bass on a given trip, only bass enters the utility function. If a person had no target, pan was entered into the utility function.

\section{B.2.2 Results}

The model was estimated for each trip taken by individuals in the sample. The coefficient estimates for each individual and each trip were summed and divided by the total number of trips to produce an average value associated with an individual trip. These aggregate parameter estimates are given in Table B.4, (Variable definitions are in Table B.5). All coefficients were of the expected sign.

(a) Aggregate species groups such as these have been used in other analyses. For example, Bockstael, McConne11, and Strand (1988) aggregate species of marine fisheries by small and big game.

(b) Because many lakes were visited by only one (or few) anglers in the sample, catch rates were often based on a single or small number of trips. Also, a lake visited by a single person targeting smallmouth bass provides no information on the catch rate of rainbow trout or any other species. For this reason, we only calculated the expected catch rate of species targeted by an individual. In constructing a person's opportunity set of lakes we included only lakes with reported catch rates of the targeted species. 
The coefficient values represent the utility associated with an incremental increase in the value of the characteristic. The coefficients for price and time cost are negative, as expected, and were quite robust across alternative specifications. Undoubtedly, an individual's probability of visiting a given site is lower if the cost of reaching the site is higher. The implied value of time for this model for individuals with fixed work schedules is approximately $\$ 7$ per hour. (The implicit value of a unit increase in the catch rate is the ratio of the value of the characteristic coefficient to the value of the price coefficient.)

The coefficients on the catch rates are positive as expected (i.e., the better the catch, the higher the probability of a trip to the lake). At any given lake, the implicit value of a unit increase in the catch rate is $\$ 0.24$ for trout, $\$ 0.37$ for bass, $\$ 0.73$ for pike, and $\$ 1.10$ for pan. The coefficients for the other site variables are all significantly different than zero.

TABLE B.4. Random Utility Model Maximum Likelihood Estimates

\begin{tabular}{lcc}
$\begin{array}{c}\text { Variable } \\
\text { Name }\end{array}$ & $\begin{array}{c}\text { Coefficient) } \\
\text { Estimate }\end{array}$ & T-Statistic \\
\cline { 2 - 3 } Price & -0.08 & 42 \\
Time Cost & -0.54 & 25 \\
Size & 0.18 & 38 \\
Boat Ramp & 0.33 & 5.9 \\
View & 0.19 & 6.1 \\
Trout & 0.02 & 3.1 \\
Bass & 0.03 & 4.3 \\
Pike & 0.06 & 3.1 \\
Pan & 0.09 & 11 \\
Same State & 0.18 & 11 \\
Log-Likelihood & -7683 & \\
\end{tabular}

(a) Significant at the 0.05 level. 
TABLE B.5. Variable Definitions

Variable

Name

PRICE

TIME

SIZE

BOATRAMP

$\mathrm{OB}$

VIEW

TROUT

T

BASS

B

PIKE
Definition

$(0.20 * 2 *$ one way travel distance $)+[$ (annua $]$ family income/1850 $x$ number of household workers) )* travel; to,e * 2)] *d

$\mathrm{d}=1$ if individual has a flexible job

$\mathrm{d}=0$ if individual has a fixed work schedule

travel time * 2* (1-d)

logarithm of the size of the lake in acres * $S$

$S=1$ if the lake size $>1000$ acres

$S=0$ if the lake size $<1000$ acres

$=1$ if lake has a boatramp

$=0$ if not

$=1$ if individual owns a boat

$=0$ if not

$=1$ through 5 , where 5 = individual strongly agreed that site was scenic and $1=$ individual strongly disagreed that site was scenic

average expected hourly catch rate of brown, rainbow, brook, lake, or unspecified trout species across all individuals targeting trout at the lake.

$=1$ if individual targeted a species in the aggregate group Trout

$=0$ if not

average expected hourly catch rate of smallmouth, largemouth, and unspecified bass across all individuals targeting bass at the lake

$=1$ if individual targeted a species in the aggregate group Bass

$=0$ if not

average expected hourly catch rate of northern pike, muskie, pickerel, and walleye across all individuals targeting pike at the lake 
IABLE B.5. (contd)

Variable

Name

PK

PAN

PN
Definition

$=1$ if individual targeted a species in the aggregate group Pike

$=0$ if not

average expected hourly catch rate of all

reported species excluding those in Trout, Bass, and Pike and excluding smelt and eel

$=1$ if the individual targeted a species in the aggregate group Pan or had no target

$=0$ if not

These numbers indicate that the probability of visiting a lake increases the better the view, the larger the lake, if a boat ramp is present (for anglers with a boat), and if the lake is in the same state in which the individual lives.

To forecast the welfare changes associated with changes in acidification, the expected utility of a fishing trip for trout was estimated using current catch rates of trout and again using projected catch rates under each scenario. The difference in expected utility is then measured in monetary terms by dividing by the coefficient on price, which is the marginal utility of income. 


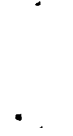




\section{APPENDIX C}

\section{PARTICIPATION ANALYSIS RESULTS}




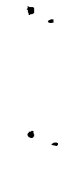




\section{APPENDIX C}

\section{PARTICIPATION MODEL ESTIMATION}

This appendix details the specification and estimation of the participation, or intensity, model. The participation model relates the number of fishing days to the catch per unit effort (CPUE), travel costs, and the demographic characteristics of the population. The predictions of the model are multiplied times individual welfare estimates (in terms of dollars per fishing day) generated by the travel cost models to derive estimates of changes in social welfare. The technique developed for this analysis utilized data from two large general population surveys of outdoor recreation behavior. These surveys (the 1980 and 1985 National Survey of Fishing, Hunting, and WildlifeAssociated Recreation) are administered every 5 years by the U.S. Fish and Wildlife Service. By utilizing these large surveys from 2 years, both the baby boom and the cross-sectional differences in angling opportunities were incorporated into the analysis.

\section{C.1 BACKGROUND}

An example of a dramatic demographic shift with intuitive appeal is the role of the baby boom generation on cross-sectionally based estimates of longterm participation rates. Demographic shifts in population, and the accompanying shifts in tastes, could have profound effects on the present value of non-market goods. A classic argument in cost benefit analysis has been to argue that as income grows the demand for the outdoor recreation and natural resources will grow. If demand were to grow at a rate greater than the discount rate, then future benefits could be more valuable then benefits today. These arguments have been based on short-term trends, not sophisticated analysis that accounts for demographic effects such as the baby boom. Indeed, this "growing outdoor recreation demand" argument first surfaced in the late 1960 s when the baby boom was just achieving adulthood. The approach described below is meant to allow a cleaner assessment of these effects, especially as they relate to recreational fishing and acidic deposition. 
This analysis models the number of fishing days an individual will take, contingent upon the decision to be a fisherman. This relationship is typically modeled along the lines of Equation (1).

$$
\text { Number of trips }=\alpha_{0}+\alpha_{1} z_{1}+\alpha_{2} z_{2}+\cdots+\alpha_{i} z_{i}
$$

In this equation, the $z i$ is the cost of fishing and the characteristics of the individual. Equations such as this predict the average number of days of fishing for an individual given the opportunities for fishing and individual characteristics. This equation permits calculation of the number of individuals who will choose to become fishermen and the number of days they will go fishing. These are precisely the numbers needed to expand an economic estimate of the value of a fishing day to the social value of fishing across an entire fishing season and across a number of years.

\section{C.2 COHORT PANEL DATA}

Data available for a study of this type are limited. The best, and most well known, data come from a series of national surveys made by the U.S. Fish and Wildlife Service. These surveys, known as the National Surveys of Fishing, Hunting and Wild-life Associated Recreation (NSFHWR), have been given to the general population every 5 years since 1955. The most recent three, 1985, 1980, and 1975, are available on computer tape. The 1970 version of the survey may also become available. These data formed the backbone for this analysis.

The best data set for the kind of analysis outlined above would be a panel data set. These data would trace the behavior of a set of randomly chosen individuals over the course of many years. The Michigan Longitudinal Study is a famous case of a data set of work force participation. Unfortunately, these kinds of data do not exist for recreational fishing. To overcome this limitation, an econometric technique developed by Deaton (1985) was applied to the data from the NSFHWR surveys. This approach combines independent cross-sections to obtain a data set.

The common sense of Deaton's (1985) suggestion is to follow cohorts rather than individuals through time. The most natural cohort definition is

$$
\text { C. } 2
$$


by age. Age is the definition used in this discussion, but many other definitions are possible (in fact, one would want to use the most disaggregate definition of a cohort available). The cohort exploits the notion that while an individual may not be followed through time, an average representative individual can. The panel data set of cohorts for recreational fishing included the average fishing behavior of people born in 1950 when they turned 30 (the NSFHWR 1980 survey) and 35 (the NSFHWR 1985 survey).

For example, consider the application only to residents of Maine. The data set was constructed as in Table C.1. In this setting, observations 1 and 2 are observations of the mean behavior of individuals born in 1950 through the 5 year time span covered by the surveys. For example, in observation 1 the value of the fishing rate and income is the 1980 average for people born in 1950. Observation 2 includes the average values in 1985 of people born in 1950. Observations 3 and 4 cover individuals born in the year 1940 over this span. Clearly, these kinds of data can be constructed for any degree of resolution that the underlying independent cross-sectional surveys or data (in this case the NSFHWR) can support.

Note that the data in Table C.1, while an unbiased estimate of the variable, are measured with error. While the mean income may be $\$ 40,000$ or the average participation rate is 0.3 , these are, indeed, averages. There are standard deviations and variance-covariance matrices associated with these estimates. This is an errors-in-variables problem. If the number of

TABLE C.1. Sample of Data from the Panel Data

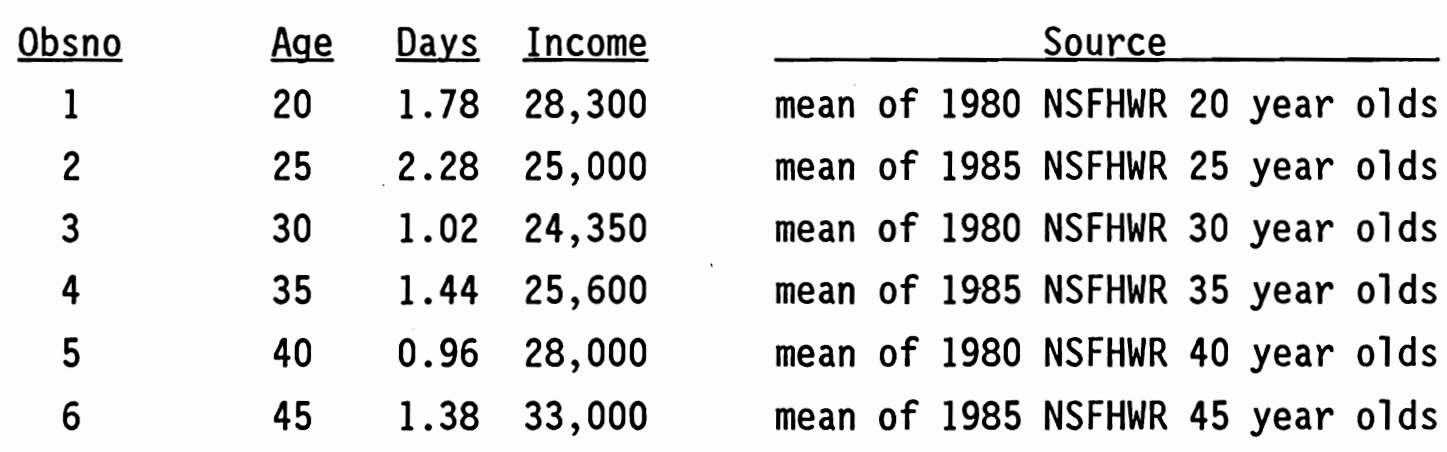


individuals in a cohort, however, is sufficiently large, the means are accurate enough that the errors-in-variables problem may be reasonably ignored. This is what was done is this analysis.

The econometric object is to transform the estimation problem into one that can be supported by the data. It should be noted that this technique may not be weaker than traditional panel data techniques. First of a11, the data are immune from attrition. Since each set is a new random sample, there is no attrition. Second, there is evidence that errors-in-variables are also a substantial problem with individual data. People do not report data accurately. The technique outlined above provides an opportunity to estimate the appropriate variance-covariances needed for consistent efficient estimation procedures when this problem exists. This approach provides a technique for bringing together independent surveys across time to estimate an inherently dynamic economic relationship.

\section{C.3 APPLICATION}

Ten different variables constructed from the NSHFWR were used in the analysis. These variables included demographic variables, age in years, nominal income in thousands, and four variables which were measured as the percentage of the cohort; urban versus non-urban, married, retired, and black. These demographic variables become percentages because of the averaging process used to create the panel data. The final variables are the CPUE and miles variables. The CPUE variables are the average CPUE by state as reported by respondents in the survey for all trout species and all bass species combined. The miles variables are the average miles traveled to bass and trout sites on a state-by-state basis as well.

The following equation was estimated using the cohort panel data.

$$
\begin{aligned}
\text { No. of trips }= & a_{0}+a_{1} \text { Age }+{ }_{2} \text { Age }^{2}+a_{3} \text { Income }+a_{4} \text { Income }^{2} \\
& +a_{5} \text { Urban }+a_{6} \text { Married }+a_{7} \text { Retired }+a_{8} \text { Bl ack } \\
& +a_{9} \text { CPUE-Bass }+a_{10} \text { CPUE-Bass }^{2}+{ }_{11} \text { CPUE-Trout } \\
& +1 \text { CPUE-Trout }^{2}+a_{13} \text { Bass-Trout }+a_{14} \text { Miles-Bass } \\
& +{ }_{15} \text { Miles-Trout }
\end{aligned}
$$


The interpretation of the coefficients is straightforward. The coefficient shows the increase in the number of days spent angling for a unit change in the independent variable. For example, retired people fish 6.1 days per year more than non-retired people. Coefficient $a_{13}$ allows for substitution between trout and bass fishing as the relative CPUEs change.

The application includes both warm water (bass) and trout fisheries. The warm water fisheries are needed to control for substitution away from trout fishing as acidic deposition damages occur. Since the biological and water chemistry models indicate that the bass fisheries will be undamaged by acidification they are not included in the simulation. Table C.2 gives the results of this regression.

TABLE C.2. Participation Model Results(a)

\section{Variables}

Constant

Age

(1.436)

Age Squared

Income

Income Squared

Urban Residence $(-6.814)$

Percent Married

Percent Retired

Percent Black

\section{Parameters}

$-1.317$

$(-0.561)$

0.201

$-0.003^{(b)}$

$(-1.96)$

1.006

$(0.901)$

$-0.095$

$(-0.506)$

$-3.091^{(c)}$

$-0.939$

$(-0.722)$

$6.161^{(\mathrm{c})}$

(3.846)

$-9.184^{(c)}$

$(-5.351)$ 
TABLE C.2. (contd)

Variables

Bass CPUE

Trout CPUE

Bass CPUE Squared

Trout CPUE Squared

Bass-Trout CPUE Interaction

Miles to Bass

Miles to Trout

R-Squared

Adjusted R-Square

Observations

\section{Parameters}

$1.794^{(c)}$

(8.622)

$1.671^{(c)}$

(8.353)

$-0.192(c)$

$(-7.189)$

$-0.187(c)$

(6.971)

$-0.047$

(1.092)

$-0.003(c)$

$(-2.408)$

$-0.0006$

$(-0.585)$

0.467

0.451

504

(a) T statistics in parentheses.

(b) Significant at the $10 \%$ level.

(c) Significant at the $5 \%$ level. 


\section{DISTRIBUTION}

No. of

Copies

OFFSITE

2 DOE/Office of Scientific and Technical Information
No. of

Copies

11 Pacific Northwest Laboratory

J. E. Englin (5)

Publishing Coordination

Technical Report Files 


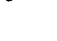

